\title{
LA CONSTRUCCIÓN HISTÓRICA DEL BENEFICIARIO: POLÍTICAS DE REGULARIZACIÓN DOMINIAL EN SANTA FE (1985-2017)
}

\section{THE HISTORICAL CONSTRUCTION OF THE BENEFICIARY: POLICIES OF DOMINANCE REGULARIZATION IN SANTA FE (1985-2017)}

\section{Emilia Mosso ${ }^{1}$}

\section{Resumen}

En este artículo nos cuestionamos sobre la relación establecida entre la instrumentalización histórica de políticas y programas urbanos -vinculados a la regularización dominial- en la configuración del orden socio-espacial reciente; y cómo esta instrumentalización contribuye a la localización espacial de la población empobrecida en la ciudad de Santa Fe, Argentina, en las últimas tres décadas. Para llevar a cabo esta propuesta, planteamos una metodología combinada de tipo cuali-cuantitativa, partiendo de una estrategia de abordaje analítica apoyada en diversos instrumentos (análisis de documentos, normativas y publicaciones, entrevistas semi-estructuradas y en profundidad, trabajo de campo, confección de mapeos y cartografías). En este marco, a partir del análisis de cuatro programas urbanos vinculados a la regularización dominial, dos de ellos instrumentalizados desde hace tres décadas, y los otros desde la última década, analizamos dicha incidencia la conformación socio-espacial santafecina y específicamente, en la localización de la población empobrecida designada por diversos organismos como beneficiaria. Reflexionamos que, mientras los programas analizados

\footnotetext{
${ }^{1}$ Es Doctora en Arquitectura por la Universidad Nacional de Rosario, Argentina. Actualmente es becaria Posdoctoral del Consejo Nacional de Investigaciones Científicas y Técnicas (CONICET). Es miembro del Instituto de Investigación en Desarrollo Urbano, Tecnología y Vivienda de la Facultad de Arquitectura, Urbanismo y Diseño de la Universidad Nacional de Mar del Plata, así como también del Grupo de Sociología y Antropología Urbana de la misma institución. Además es colaboradora del Taller de Estudios Metropolitanos de Facultad de Arquitectura, Diseño y Urbanismo de la Universidad Nacional del Litoral, y actualmente se desempeña como docente de la asignatura Taller de Proyecto Urbano de la misma institución. Su línea de investigación actual es política urbana de suelo y vivienda. Entre sus últimas publicaciones destacan: "Interpelaciones ideológicas sobre la vivienda. Políticas urbanas de ordenamiento espacial de la población empobrecida en Santa Fe (1985-2017)", tesis doctoral, Universidad Nacional de Rosario, Argentina, (2017); "Políticas \{neoliberales\} de regularización dominial del suelo urbano", en Cuaderno Urbano, $N^{\circ}$ 22. Nobuko: Resistencia, Volumen 22 N.²2, pp. 91-110 (2017); en co-autoría "Epistemologías del espacio alienado. Exploraciones sociogenéticas en torno al conflicto social ", en "Epistemologías del (Des)orden Territorial" Núñez (coomp.), Mar del Plata: EUDEM, (2016). Teléfono (+54) 342 5045245. E-mail: emiliamosso@gmail.com
} 
incorporan diversos instrumentos de política en pos de regularizar dominialmente la propiedad, la contradicen: se trata de la instrumentalización histórica de una política pública que promulga, avala y defiende la propiedad, pero que reproduce condiciones de tenencia precaria.

Palabras clave: Política urbana - regularización dominial - orden socio-espacial - población empobrecida

\begin{abstract}
In this article we question the relationship established between the historical instrumentalization of urban policies and programs-linked to the dominance regularization - in the configuration of the recent socio-spatial order; and how this instrumentalization contributes to the spatial localization of the impoverished population in the city of Santa Fe, Argentina, in the last three decades. To carry out this proposal, we propose a combined qualitativequantitative methodology, based on a strategy of analytical approach supported by various instruments (analysis of documents, regulations and publications, semi-structured and in-depth interviews, field work, clothing of mappings and cartographies). In this framework, from the analysis of four urban programs linked to the dominance regularization, two of them instrumentalized for three decades, and the others since the last decade, we analyzed this incidence the socio-spatial conformation in Santa Fe and specifically, in the location of the impoverished population designated by various agencies as beneficiary. We reflect that, while the analyzed programs incorporate various policy instruments in order to regulate property ownership, they contradict it: it is the historical instrumentalization of a public policy that promulgates, endorses and defends property, but that reproduces conditions of precarious tenure.
\end{abstract}

Keywords: Urban policy - dominance regularization - socio-spatial order - impoverished population 


\title{
CONSIDERACIONES INICIALES
}

La reestructuración capitalista operada desde la década de 1980 hasta la actualidad², signada por la hegemonía del capital financiero, manifiesta los presagios de las crisis sobre los trabajadores y la población empobrecida en las ciudades latinoamericanas (Núñez y Ciuffolini, 2011). ¿De qué manera? a partir el continuo deterioro de las condiciones de vida, hacinamiento, promiscuidad, insalubridad e inestabilidad económica, social, jurídica y habitacional, entre otras cuestiones (Pradilla, 1983). En estas condiciones históricas de acumulación del capital, parte de la población latinoamericana habita en precarias condiciones de vida, en consonancia con lo que Lucio Kowarick (1979, 2000:22) describe como expoliación urbana:

\begin{abstract}
"la sumatoria de extorsiones que se operan por la inexistencia o precariedad de servicios de consumo colectivo, que conjuntamente con el acceso a la tierra y a la vivienda, se presentan como socialmente necesarios para la reproducción de los trabajadores y agudizan aún más la dilapidación que deriva de la explotación del trabajo o, lo que es peor, la falta de este".
\end{abstract}

Varios autores acuerdan en considerar el papel del Estado en este proceso como un organismo determinante en los factores de valorización diferencial del suelo (Smolka, 1979; Pradilla: 1983; Kowarick: 2000, Duhau: 2002). ¿En qué sentido? Mediante el establecimiento de políticas, programas, proyectos y demás reglamentaciones que establecen y legitiman los usos del suelo, y hacen al proceso de especulación inmobiliaria y diferenciación social, entre otras cuestiones; e inciden en las posibilidades de localización y permanencia de la población. Considerando a estas, como aquellas políticas urbanas que contribuyen, mediante la operacionalización de diversos instrumentos de política -normativas, programas, proyectos, planes, etc.- a la localización espacial de la población empobrecida en sectores urbanos precarizados; en ciertos casos sobre suelos difícilmente aptos para su residencia, localizados en zonas de riesgo hídrico y ambiental, desprovistos de servicios, infraestructuras, equipamientos,

\footnotetext{
2 El presente artículo constituye un extracto de nuestra tesis doctoral denominada " $x$ ", cuyo objetivo fue profundizar el debate sobre las interpelaciones ideológicas presentes en diversos instrumentos urbanos entre ellos, políticas, planes, programas, proyectos y normativas-, y su vinculación con los postulados neoliberales promulgados por organismos internacionales, principalmente por la Organización de las Naciones Unidas, desde las últimas cuatro décadas en la ciudad de Santa Fe, Argentina. Dicha investigación estuvo enmarcada en la Beca Doctoral de CONICET (período 2013/2018) y en el proyecto colectivo PICT 2013-2053, FONCyT/ANPCyT, ambos con la dirección de la Dra. Arq. Ana Núñez (IIDUTy Yv/FAUD, UNMdP). Asimismo, nos encontramos profundizando en esta línea de investigación a través de la Beca Posdoctoral de CONICET (período 2018/2020) también con la dirección de la Dra. Arq. Ana Núñez.
} 
con condiciones habitacionales y de tenencia precarias, entre otras cuestiones; comprendiendo a su vez al cúmulo de aspectos que hacen a las condiciones generales de reproducción (Pradilla, 1984). Estas últimas, definidas en torno a las relaciones sociales establecidas históricamente, indicen en la localización espacial de la población, de los hogares, de las viviendas, y de sus condiciones; y hacen a la división social del espacio, entendiendo a esta como a "la relación existente entre la composición social y de clase de una sociedad y su manifestación en la estructura del espacio habitado" (Duhau, 2013:79).

Dentro del cúmulo de políticas urbanas que posiblemente incidan en la localización y permanencia de la población empobrecida encontramos, en el ámbito latinoamericano, los programas de regularización dominial del suelo ${ }^{3}$. Estos programas reconocen su instrumentalización en las últimas décadas de forma masiva en sectores urbanos precarizados de nuestras ciudades, y se encuentran financiados en su mayoría por organismos internacionales y bilaterales de crédito ${ }^{4}$. No obstante, en las últimas dos décadas, los mismos se han constituido en un campo discursivo hegemónico en política urbana (Autora, 2017a), encontrando este sustento en diversas lógicas del arte de gobierno neoliberal ${ }^{5}$ (Murillo, 2015).

En este contexto, en este artículo nos cuestionamos sobre la relación establecida entre la instrumentalización histórica de políticas y programas urbanos -vinculados a la regularización dominial- en la configuración del orden socio-espacial reciente; y cómo esta instrumentalización contribuye a la localización espacial de la población empobrecida en la ciudad de Santa Fe en las últimas tres décadas. Para comprender esta relación, y a partir de una metodología combinada de tipo cuali-cuantitativa, y una estrategia de abordaje analítica apoyada en diversos instrumentos (análisis de documentos, entrevistas semi-estructuradas y en profundidad a informantes claves, trabajo de campo y confección de mapeos y cartografía), seleccionamos cuatro programas urbanos vinculados a la regularización dominial, que desde mediados de la década de 1980 indicen en esta configuración; y encuentran su punto de contacto en el territorio.

\footnotetext{
${ }^{3}$ Según el Banco Interamericano de Desarrollo, estos programas consisten en la legalización de la tenencia de tierra a familias que residen en sectores urbanos precarizados, e implican estudios, trámites, y acciones para la regularización física del área a intervenir y la regularización legal necesaria para realizar la transferencia de la titularidad del dominio de las tierras a favor de los hogares beneficiarios.

${ }^{4}$ Entre ellos la Organización de las Naciones Unidas, UN-Hábitat, el Banco Mundial y los bancos regionales de desarrollo.

${ }^{5}$ Neoliberalismo, en el sentido de Murillo (2015:13), no solo como estrategia económica, sino también como lógica que en diversos niveles, "intenta configurar a la cultura hegemónica en el sentido de gestar procesos de subjetivación que tratan de controlar la vida en todos sus aspectos".
} 
El primero de ellos es el Plan Logro de un Ordenamiento Territorial Estable -en adelante Plan Lote- instrumentalizado por el gobierno provincial de Santa Fe, el cual basó su primicia en la regularización dominial del suelo para hogares que desde hacía al menos dos décadas residían en viviendas sin la propiedad de lote. El segundo antecedente es el Programa de Erradicación de Ranchos - desde adelante PER- del Movimiento Los Sin Techo -en adelante MLST-, programa que también desde el año 1985 es instrumentalizado en la ciudad a partir de la construcción de módulos habitacionales mínimos en sectores urbanos precarizados empero sin otorgar escrituras de dominio, sino promoviendo posteriormente la expropiación de estos terrenos o bien articulado con el gobierno para la regularización de la propiedad.

El tercer antecedente es el Programa de Regularización Dominal -en adelante PRDinstrumentalizado desde el año 2009 por el municipio de la ciudad, y desde el 2011 por la Agencia Hábitat Santa Fe, el cual retoma sectores urbanos precarizados ya comprendidos con anterioridad por los dos programas antes mencionados. Finalmente, los Programas Urbanos Integrales -en adelante PUI- instrumentalizados desde el año 2012 desde la Secretaría de Estado de Hábitat de la provincia, que en articulación con el PRD adquieren otra metodología: o bien se regulariza la propiedad de suelo en donde se asientan los hogares y sus viviendas, o bien se relocaliza a la población a nuevas viviendas, interpelando en este caso también sobre la tenencia segura. ¿Qué es lo que comparten, a grande rasgos, estos programas? si bien cada uno tuvo génesis en instituciones diferentes -distintos niveles del estado, organizaciones sociales y entes financiantes-, los mismos comparten las interpelaciones ideológicas basadas en la tenencia segura ${ }^{6}$ como solución al problema socio-habitacional para la población empobrecida (Autora, 2017b).

\footnotetext{
${ }^{6}$ Con tenencia segura nos remitimos a las conceptualizaciones emitidas por la Organización de las Naciones Unidas desde finales de la década de 1980 y principios de la década de 1990 (Fernandes, 2003, Clichevsky, 2006, Kozak, 2016); cristalizadas puntualmente en el año 1996 cuando tuvo lugar la Conferencia de la ONU sobre los Asentamientos Humanos -HABITAT II-. En este encuentro, a modo general, se establece el andamiaje conceptual de la seguridad de la tenencia como uno de los objetivos primordiales que deben proseguir los gobiernos a nivel mundial. Desde este período, la mayoría de los organismos internacionales de crédito redireccionaron su financiamiento -que venía siendo destinado hacia políticas de construcción de viviendas- hacia la legalización de la propiedad del suelo en donde residen familias en condiciones de tenencia precaria (Autora, 2017b).
} 


\section{EL DESENVOLVIMIENTO TERRITORIAL DE SANTA FE}

El proceso expansivo de ocupación del suelo que establece el orden socio-espacial de la población en la ciudad de Santa Fe, localizada en el centro de la región pampeana argentino, inicia a comienzos del siglo XIX, y se encuentra vinculado al incremento de los precios internacionales de los productos agropecuarios durante el modelo de acumulación agroexportador. Creada en 1573 por Juan de Garay en la actual Cayastá, la ciudad se desarrolla a partir de 1951 en su localización presente ${ }^{7}$. Su trazado, cuyo origen remota al damero colonial, establece desde su fundación el orden socio-espacial de la colonización: la ciudad parte de un epicentro ubicado en el centro-sur, a partir de la localización del puerto, y se expande en el sentido norte a través de un damero continuo, jerarquizado por la secuencia de bulevares (Soijet, 2011). Allí se localizan de manera desigual, como en un cúmulo de ciudades latinoamericanas, la población según sus condiciones de clase.

La división socio-espacial de la ciudad se constituye, en este sentido, a partir del núcleo central organizado por la plaza y los edificios institucionales junto con las tierras asignadas a los principales terratenientes, y a las afueras de este trazado se localiza el resto de la población ${ }^{8}$, siguiendo las Leyes de Indias establecidas en la colonia. Sin embargo desde su génesis, Santa Fe no es ajena al complejo proceso social de relaciones establecidas en la colonización: (1) el orden social de la colonia establece el orden espacial de la población, manifestándose en la estructura de la ciudad; y (2) este orden espacial es a su vez fundado sobre suelo propicio a las crecidas del río, por su propia condición geográfica.

Entre los años 1856-1930, se encuentra en correlación con la compleja red de relaciones que viabilizó la división internacional del trabajo durante el modelo de acumulación agroexportador (Núñez, 2012:53). En este periodo se destaca a nivel urbano, la instauración de redes ferroviarias a partir del año 1884, la habilitación hacia 1010 de un sector industrial-

\footnotetext{
${ }^{7}$ Capital provincial y ciudad cabecera del departamento La Capital se localiza en el centro-oeste de la Argentina en la denominada geográficamente región pampeana, a orillas del Río Salado y de la Laguna Setúbal, ambos tributarios del Río Paraná. La misma se encuentra geográficamente delimitada en su mayoría por límites de carácter fluvial: al este, el Río Paraná; al oeste, el Río Salado; al norte, limita con la ciudad de Recreo; y al Sur, comprende el territorio entre el río Santa Fe y su confluencia con el Río Salado y las islas adyacentes hasta el Paraná. La jurisdicción territorial del Municipio abarca 26.800 hectáreas, de las cuales, más de un 70\% está conformado por ríos, lagunas y bañados.

8 Para ese periodo se registró una población total de 5749 habitantes, siendo el 47\%, es decir, 2714 de pobladores de origen europeo o criolla, 31\%, 1810 pobladores de población esclava y parda, y un $22 \%$ 1238 habitantes- de origen aborigen y chino.
} 
portuario con en el puerto de ultramar integrado a la ciudad y la apertura del Boulevard Gálvez a fines del S.XIX, que para ese entonces constituía el límite norte de la ciudad. Siguiendo a Gómez y Peretti (2013), esta traza posibilitó la expansión urbana hacia el frente ribereño de la laguna Setúbal, estableciéndose ya para ese momento la franja este de la ciudad como sector residencial junto a edificaciones institucionales dominantes.

Con el suelo sobre cotas de mayor altura ya ocupado desde la fundación por la clase burguesa, así como la apropiación de la franja ribereña al este y la franja este-oeste de los bulevares; comienzan a ser apropiadas franjas de suelo sobre el borde oeste próximas al centro físico de la ciudad, en precarias condiciones infraestructurales de localización. Es decir, en las tierras ganadas al amplio valle de inundación del Río Salado. Así es como durante las tres primeras décadas del S.XX se asientan con mayor intensidad fracciones sociales empobrecidas sobre la franja sur-oeste de la ciudad.

Situándonos en la década 1930, tiene inicio el modelo de industrialización por sustitución de importaciones -ISI-; que comprende dos etapas. Un primer periodo que abarca desde 1930 hasta la segunda guerra mundial de 1945, y un segundo periodo desde ese año en adelante, atravesada en el año 1976 por la dictadura cívico-militar ${ }^{9}$. Varios autores coinciden en considerar la localización de los primeros 'asentamientos informales' sobre el oeste del municipio de Santa Fe (Gioria, 2009; Gómez y Peretti, 2013), "fundamentalmente sobre los terrenos de escasa altitud y escaso valor inmobiliario" (Gómez y Peretti, 2013:12). En este marco, hacia 1940 fueron operacionalizadas las primeras obras de infraestructura de protección contra las crecidas del Río Salado. Entre ellas, la construcción de un terraplén -Irigoyen-. La concreción de esta obra posibilitó, quizá, el incremento de la población empobrecida localizada sobre suelo asentado sobre el valle de inundación al oeste de la ciudad. Con la crisis del fordismo del año 1973, tiene inicio la instauración del modelo económico neoliberal, aun presente en nuestro días ${ }^{10}$. Durante este periodo, el tratamiento sobre las problemáticas socio-

\footnotetext{
${ }^{9}$ Durante este tramo se observaron altas tasas de crecimiento poblacional. Principalmente entre los años 1914 y 1947, período en el cual la población asciende de 59.574 a 168.791 habitantes, registrándose una población de 208.350 habitantes entre las décadas 1960 y 1970; y entre 1970 y 1980, con un incremento de 244.256 a 307.788 habitantes, impulsados en el primer período por el impacto del proceso migratorio transoceánico y el segundo, por un leve repunte de la fecundidad junto a la llegada de migrantes internos (Gómez y Peretti, 2013). Ya para el año 1960 el CNPHV registró una población de 208.350 habitantes, incrementándose en el año 1970 a 257.241 habitantes.

${ }^{10}$ De acuerdo con Gioria (2009), el 41,6\% de la población para principios de la década de 1970 residía al oeste de la Av. Urquiza; y ya se localizaba en ese momento sobre tierras fiscales. En el año 1980, se registra un población total de 306.293 y un 50,8\% de la población -155.765- residiendo al oeste de la Av.
} 
espaciales refirió, principalmente, a: 1) las migraciones internas, identificadas en parte por el empobrecimiento evidenciado al norte provincial, a partir del cierre de las fábricas de tanino, y de la provincia de Chaco'il; y 2) el establecimiento de industrias en otras localidades del aglomerado, a partir de la constitución del Parque Industrial en Sauce Viejo (Gioria, 2009). No obstante, será a partir de la dictadura cívico-militar de 1976 donde comienzan a registrarse los primeros procesos de relocalización de población empobrecida ${ }^{12}$. Con el retorno democrático desde mediados de la década de 1980 en Argentina, damos inicio a nuestro análisis, cuestionándonos inicialmente: ¿Qué relación se establece entre este desenvolvimiento territorial histórico en el orden social reciente?, y, ¿Cómo repercute en las posibilidades de localización de la población empobrecida en la actualidad?

\section{El Plan Lote, 1985}

En el año 1985 se detectaron en la ciudad, a partir de un relevamiento social y cartográfico realizado por el gobierno provincial, los asentamientos urbanos que para ese momento presentan irregularidades en la tenencia del suelo. La política que vino a instrumentalizarse en este contexto fue el Plan Logro de un Ordenamiento Territorial Estable, conocido como Plan LOTE, cuyo alcance provincial solo tuvo aplicación en las ciudades de Rosario y Santa $\mathrm{Fe}^{13}$. Este plan consistió uno de los primeros programas de regularización

Urquiza. Para 1991, del total de la población de la ciudad - 349.323habitantes - más de la mitad -185.674 habitantes- esto es, el 53,1\%, se encontraba residiendo en esta localización. En este marco, en el transcurso de 21 años mientras que la población total se incrementó en 92.092 habitantes, el incremento de la población que residía en al Oeste de Av. Urquiza fue de 78.657. Resumidamente, mientras que en periodo 1970/1980 la TAC (0/00) del total de la población fue de 17,4, hacia el oeste la misma duplicó el incremento por más del doble, siendo de 37,1. En el periodo que continua, 1980/1991 la TAC (0/00) del total de la población fue inferior al periodo anterior, 13,1 así como la misma la población al oeste se redujo a la mitad. Es decir, que el periodo 1970/1980 es donde apreciamos una mayor ocupación de suelo vacante sobre esta franja oeste, aunque en condiciones ambientales, infraestructurales y de servicios precarias.

${ }^{11}$ Según el informe realizado por el MSLT "El sector marginado en Santa Fe. Un informe para debatir y preparar el futuro de Santa Fe" (1997) entre los años 1975/1980, de cada diez familias asentadas en precarias condiciones habitacionales, al menos dos de las mismas presentaban trayectorias migratorias.

12 Se trata de población asentada sobre terrenos municipales localizados al noroeste de la ciudad próximos a Mariano Comas y Facundo Zuviría-; que residían sobre vagones y depósitos pertenecientes a la cervecería Quilmes. Surge así el barrio Santa Agustín 1, a partir de un programa de autoconstrucción llevado a cabo por la Dirección de Bienestar Social de la Municipalidad de la ciudad.

13 Debido a la dificultad que se nos presentó para obtener información sobre este plan, pero reconociendo la importancia de su operacionalización en relación a las condiciones de localización de la población en la actualidad, este acápite fue elaborado fundamentalmente a partir de entrevistas en 
dominial del suelo de amplio alcance en la ciudad. Con el mismo se buscó, fundamentalmente, la regularización dominial de los lotes en dónde residían hogares en condiciones precarias de tenencia desde hacía 10, 15 o 20 años (Mapa № 1). En este marco, este plan comprendió dos momentos claves: un primer relevamiento social realizado en el año 1985, y otro realizado posteriormente en el año 1995. En ambas instancias, el organismo de instrumentalización encargado fue la "Dirección Provincial de Ordenamiento Territorial", ente residual en la década posterior; y el valor fiscal de los inmuebles fue determinado por la "Junta Central de Valuaciones del Servicio de Catastro e Información Territorial de la Provincia de Santa Fe". Esta junta estableció un valor fiscal y social para estos terrenos, inferior a los precios establecidos en el mercado inmobiliario de ese momento.

\section{Mapa 1 Plan Lote: localización espacial de hogares con condiciones precarias de tenencia, Santa Fe, 1985.}

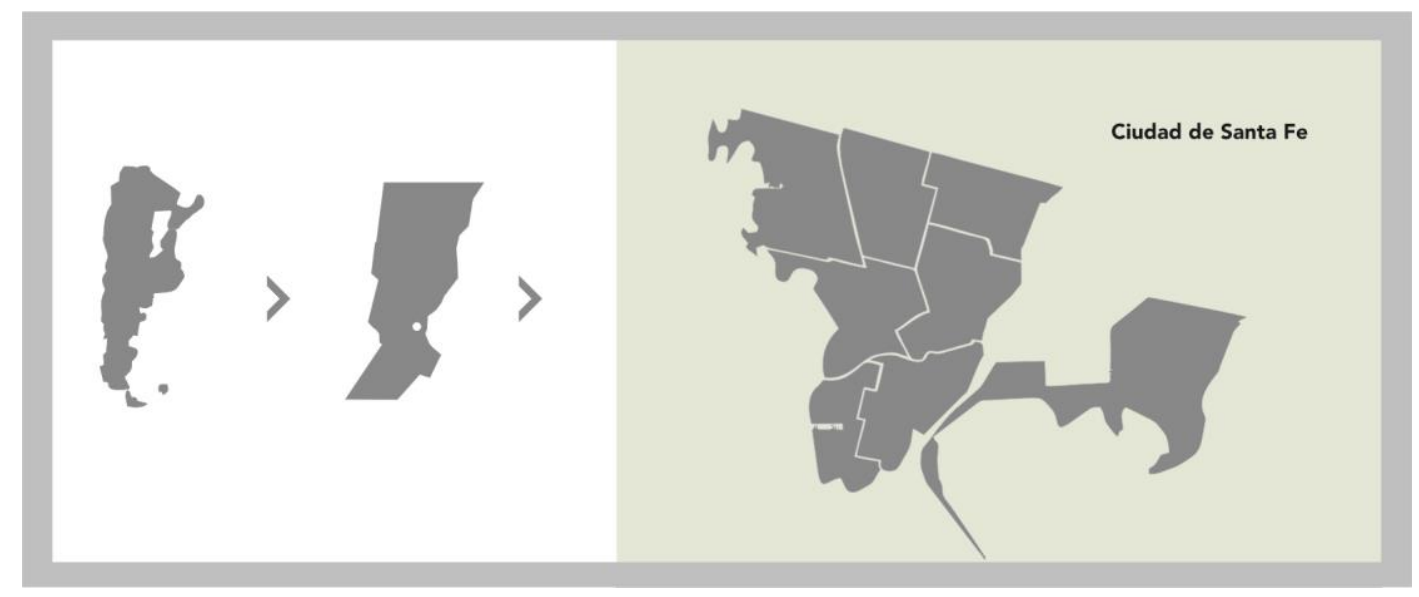

Fuente: elaboración propia recabada en el trabajo de campo según entrevistas propias realizadas entre los años 2015-2017a funcionarios de la DPVyU, ex trabajadores de Plan LOTE.

Para los casos de aquellos terrenos cuyo dominio eran de propiedad municipal así como los pertenecientes a la "Dirección Provincial de Vivienda", se realizaron convenios con este organismo para lograr la regularización dominial. No obstante, para el caso de terrenos de

profundidad personales realizadas a dos informantes claves. El primero de ellos, es un ex trabajador de Plan Lote que actualmente se desempeña en la Dirección de Emergencia Habitacional de la DPVyU. Nuestro segundo informante, es el coordinador del Programa de Erradicación de Ranchos del MLST. Ambos funcionarios, desde distintas perspectivas, han sido participes de Plan Lote desde su inicio. 
dominio privado, fueron instrumentalizadas dos leyes de expropiación, ambas, originarias de plan Lote. Se trató por un lado, de la Ley Provincial № 9982 de "Expropiación: inmuebles ubicados en las ciudades de Santa Fe y Rosario, para lotear entre sus actuales ocupantes - Plan Lote -" sancionada en el año 1986 por el Poder Legislativo de la Provincia de Santa Fe. Y en consonancia, de la Ley №10076 de "Expropiación: de inmuebles en Santa Fe y Rosario ubicados en villas de emergencia. Se los incluye en plan Lote", sancionada en 1986 también por el poder legislativo. A través de estas leyes, los inmuebles comprendidos fueron declarados de utilidad pública. Con la intención de someterlos a las expropiaciones correspondientes para la futura transferencia a la provincia y luego a los hogares:

"Se comenzaron a comprar esos terrenos privados, a través de convenios de advenimiento (...). Sino había acuerdo, se hacía un depósito judicial en tribunales para el día de mañana la provincia tener el dominio y llegar al objetivo que era la regularización." (Entrevista ex trabajador Plan Lote, AlOl 18/04/2017)

Según nuestro trabajo de campo, y en relación a los resultados alcanzados por este plan a lo largo de la década en que se instrumentalizó (1985-1995), hemos podido corroborar la prevalencia de la entrega de instrumentos precarios de tenencia, y no de escrituras que acrediten el dominio definitivo a los familias: i) en los barrios en donde residían familias en condiciones precarias de tenencia sobre dominio provincial -Santa Rosa de Lima, Villa Hipódromo, San Lorenzo y los Hornos Sur-; se entregaron boletos de compraventa y se realizaron trabajos de urbanización (relleno de cavas, apertura de calles, loteo de manzanas, entre otros.). Estos boletos no superaron el $10 \%$ del ingreso del salario del grupo familiar; ii) en el barrio Santa Rosa de Lima de lotearon y entregaron boletos de compraventa en 8 manzanas, cada una con aproximadamente 40 familias -320 familias en total-; iii) en el barrio San Lorenzo, el trabajo se efectuó en 4 manzanas de dominio provincial y 2 de dominio municipal, es decir, 240 familias; iiii) en los barrios Los Hornos y Villa Hipódromo, se entregaron boletos de compraventa en dos manzanas en cada uno, es decir, 240 familias aproximadamente; iv) a su vez, en los barrios Barranquitas y 12 de Octubre, cuyo dominio era municipal, se entregaron aproximadamente el 95\% del total de las manzanas relevadas.

La modalidad de instrumentalización del plan, consistió en la instalación de unidades de ordenamiento en algunos de los barrios a regularizar: Alto Verde, Yapeyú, Villa Hipódromo, Santa Rosa de Lima, Los Hornos Sur, San Lorenzo, Barranquitas y 12 de Octubre. Estos barrios, en su mayoría, eran de dominio privado, cuestión que según uno de nuestros informantes claves dificultó la regularización: 
"En las manzanas expropiadas la dificultad más grande que teníamos con el plano de mensura, era que no estaba saneado el dominio. Ósea se había expropiado, se había pagado, pero no se había inscripto por alguna circunstancia" (Entrevista ex trabajador Plan Lote Al-OI 18/04/2017).

No obstante, a pesar de que no se hayan entregado las escrituras de dominio en la mayoría de los barrios, si fueron otorgados boletos de compraventa del lote como instrumento de legitimación. Sin embargo, este problema que inicia a mediados de la década de 1980 continúa hasta el día de hoy en muchos de estos barrios como veremos a continuación: al no encontrarse inscripto el dominio de estos lotes, no es posible aprobar las mensuras de los planos y por lo tanto, tampoco es posible otorgar la escritura de dominio a las familias:

"El error fue haber entregado boleto de compraventa, porque esta tan dinámico todo en esos asentamientos. La gente vende, compra, se lo pasan a los hijos, un hijo le vende. Entonces hacer el boleto de compraventa no era una solución definitiva porque el problema hasta el día de hoy, después de casi 30 años sigue existiendo." (Entrevista ex trabajador Plan Lote AI-OI 18/04/2017).

Como veremos más adelante, esta cuestión será reiterada en otros los programas investigados. En cuanto a los hogares asentados sobre terrenos de dominio provincial, también fueron entregados boletos de compraventa:

"en las tierras provinciales donde se expropio, nunca se entregó una escritura, si se entregaron en donde se hizo convenio entre municipalidad y vivienda. La municipalidad si hizo boleto, y (...) algunas escrituras. Y vivienda también hizo boleto" (Entrevista ex trabajador Plan Lote Al-OI 18/04/2017).

Es decir, que a pesar de una década de trabajo en este programa, muchos de los hogares que desde hace ya 20 años para ese momento no poseían el dominio del suelo, aún no hay podido regularizar la situación ${ }^{14}$. Esto implico que si bien algunas familias han recibido la escritura, en otros casos solo han obtenido los boletos de comprar venta, aun cuando estas han efectuado el pago de las cuotas de sus lotes:

"Haces que la gente page el terreno, aunque sea en dos o tres cuotas, o al contado, algo simbólico (...) Entonces cumplís la función social que es entregar la escritura y te sacas un problema de encima. Porque toda la dinámica que venga después no te compete como Estado. Yo cumplí entregándote la escritura." (Entrevista ex trabajador Plan Lote Al-Ol 18/04/2017)

\footnotetext{
${ }^{14}$ Según nuestros informantes claves desde hace cinco años se ha retomado parte de este trabajo en los barrios Villa de Parque, Villa Elsa y los Hornos Norte, donde el dominio del suelo se encontraba inscripto a favor de la provincia.
} 
El Plan Lote tuvo injerencia hasta el año 1994, cuando quedo como un ente residual. Posteriormente a la instrumentalización del mismo, en el año 2004 tuvo lugar el "Programa Nacional Arraigo" bajo el Decreto $N^{\circ} 835 / 2004$, cuyo fin fue la creación de un registro denominado "Banco Social de Tierras", en el ámbito de la "Comisión de Tierras Fiscales Nacionales". Este programa buscó, a partir de la creación de este registro, disponer de información sobre inmuebles de dominio privado del Estado Nacional que pudiesen ser afectados a fines sociales. Concomitante, en el año 1994 se sancionó la “Ley Nacional Pierri”"15, que veremos a continuación.

En este contexto, hacia el año 1995 se registraban en la ciudad aproximadamente 21 asentamientos urbanos en donde residían hogares con condiciones precarias de tenencia ${ }^{16}$. Es decir, que en una década se habían incrementado cualitativa y cuantitativamente las hogares residiendo en la ciudad con estas condiciones. De esta cantidad, 14 asentamientos se encontraban sobre suelo de dominio privado sujetos a expropiación. A grandes rasgos, estos hogares en su mayoría residían sobre suelo localizado en el borde oeste de la ciudad, así como en la zona costera de Alto Verde, y parte en el norte (Mapa $\mathrm{N}^{\circ} 2$ ).

15 Cuya aplicación en la ciudad de Santa Fe tiene incumbencia en la actualidad desde la Secretaría de Desarrollo Social de la Provincia.

${ }^{16}$ Lamentablemente, no disponemos información sobre la cantidad de familias residiendo en condiciones precarias de tenencia en estos barrios. 
Mapa 2 Plan Lote: localización espacial de hogares con condiciones precarias de tenencia inconclusos, Santa Fe, 1995.

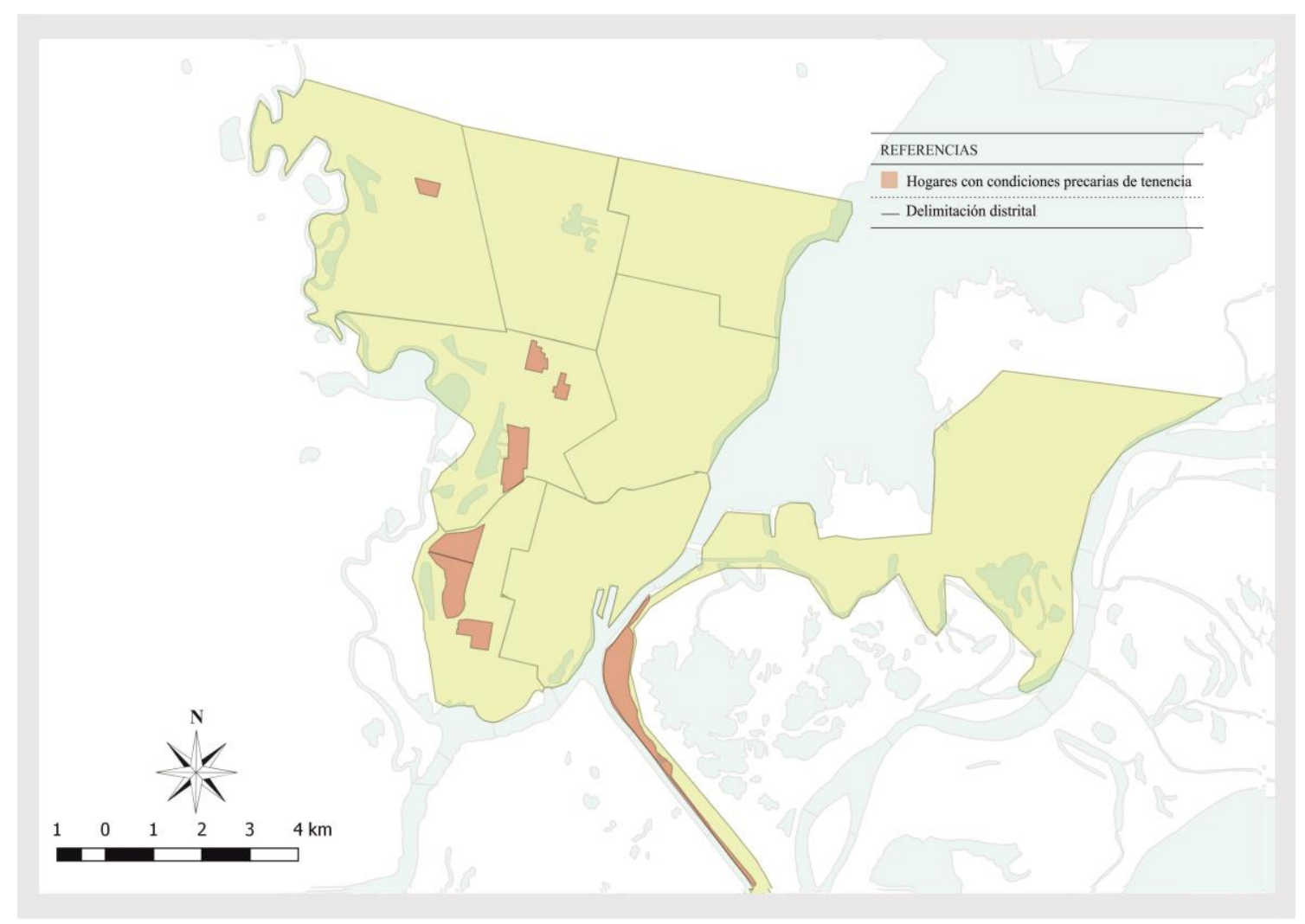

Fuente: elaboración propia recabada en el trabajo de campo según entrevistas propias realizadas entre los años 2015-2017a funcionarios de la DPVyU, ex trabajadores de Plan LOTE.

Sin embargo, como apreciaremos a continuación, la mayoría de los barrios que desde este periodo residían hogares empobrecidos localizados sobre inmuebles de dominio privado, fueron incluidos en el PRD, y reconocen su génesis en el MLST a través de su PER.

\section{El Programa de erradicación de ranchos, 1985}

En paralelo a la instrumentalización de Plan Lote, desde el año 1985 comienza a operacionalizarse en la ciudad un programa de vivienda y loteo que tiene por objeto a la población empobrecida. Nos referimos al PER, realizado por el MSLT, organización social de corte religioso constituida en 1986, año desde el cual continúa sus actividades 
ininterrumpidamente ${ }^{17}$. La mayor parte de su producción socio-habitacional se encuentra distribuida en aproximadamente 22 barrios, localizados principalmente sobre el borde oeste y noroeste de la ciudad (Mapa $\mathrm{N}^{\circ} 3$ ).

Mapa 3 Programa de Erradicación de Ranchos: localización espacial de prácticas asistenciales y módulos habitacionales en donde residen hogares con condiciones precarias de tenencia, Santa Fe, 1995-2010.

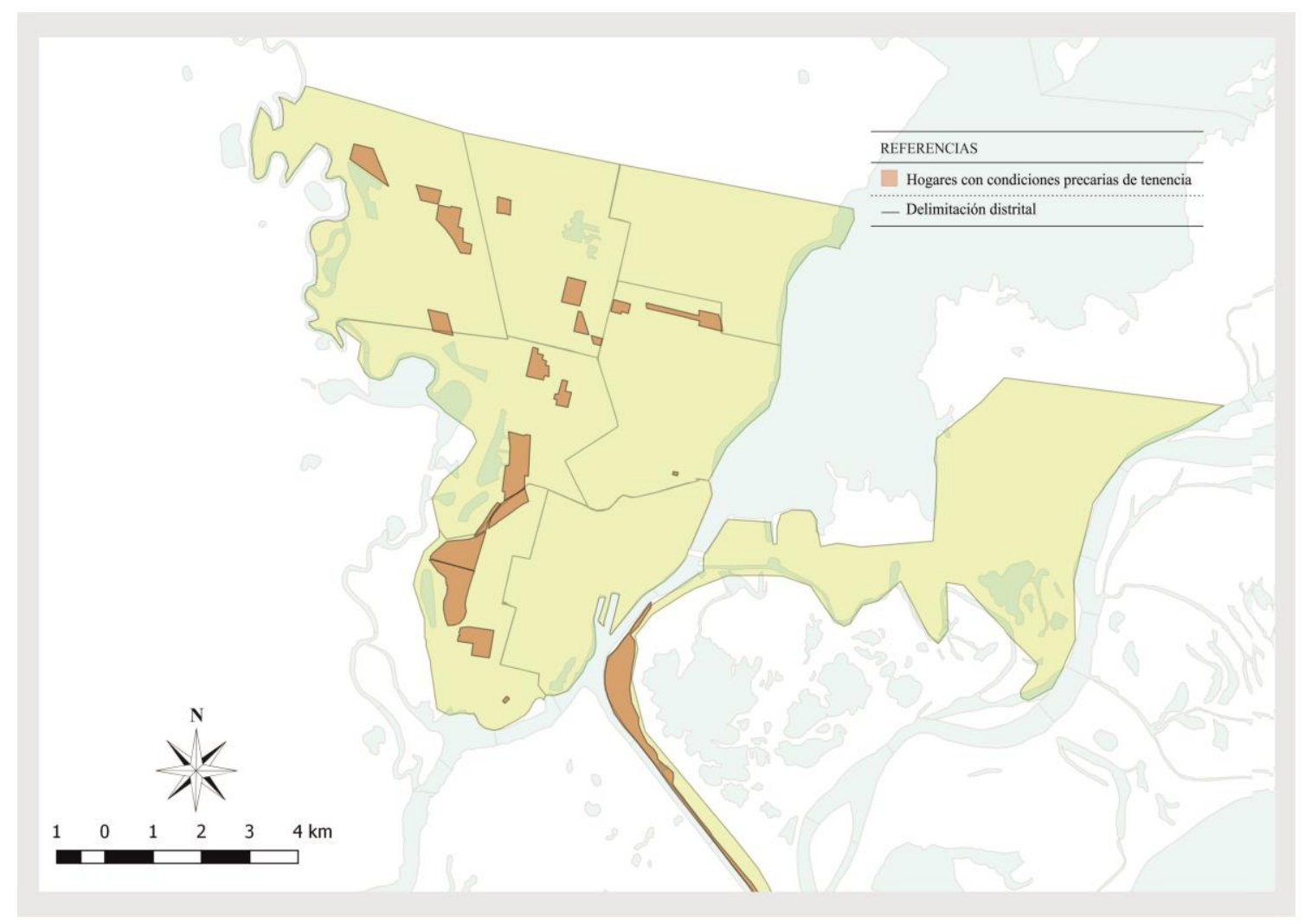

Nota: las prácticas asistenciales del MLST comprenden la construcción de viviendas y la prestación de servicios en las sedes que dispone: jardines maternales, aulas de capacitación informática, centros de salud, comedores y copa de leche. Fuente: elaboración propia recabada en el trabajo de campo según entrevistas propias realizadas entre los años 2015-2017a referentes del MLST.

17 Entre las diversas fuentes de financiamiento desde el año de su fundación hasta la actualidad, se destacan la cooperación internacional, el aporte de empresas privadas, de organismos estatales en distintos niveles, el aporte de fondos propios, de fundaciones internacionales, fundaciones nacionales y fondos provenientes de otras entidades religiosas. 
Sucintamente, hacia el año 1987 los primeros planes de esta organización contaron con el cofinanciamiento de la Cooperativa NCIV de Holanda, la Fundación Misereor Alemania y Advenia Roma para la construcción de 1000 unidades habitacionales por ayuda mutua y esfuerzo propio ${ }^{18}$. Sin embargo, estos planes fueron operacionalizados en diez barrios Centenario, Villa Hipódromo, Las Lomas, Los Hornos, La ranita, Alto Verde, Villa Elsa, San José, Chaqueño y Los Naranjos-, que involucraban aproximadamente a 5500 familias, sobre suelo de dominio privado. Esta cuestión es central para comprender la posterior injerencia ejercida por el MLST en la Ley de expropiación de suelos. Hacia el año 1989 fueron financiadas otras 1500 viviendas por la Fundación Misereor de Alemania, también por ayuda mutua y esfuerzo propio; hasta el 1993, en donde tuvo lugar el primer cofinanciamiento conjunto realizado por la Provincia de Santa Fe, la Secretaría Desarrollo Social Nación y la Unión Europea ${ }^{19}$.

Según el Censo "Datos sociales del sector Marginado" realizado por esta organización en el año 1996, en la ciudad de Santa Fe residían para ese entonces 1475 familias en ranchos, que hacían aproximadamente un total de 6000 personas viviendo en condiciones sociohabitacionales precarias. Este censo relevó a su vez la localización geográfica de las familias que residían en los ranchos, a saber: Alto Verde (219 familias), El Abasto (129 familias), Las LomasCabal (104 familias), San Pantaleón (104 familias) y Pompeya (101 familias). A su vez, Villa Hipódromo (56 familias), Varadero Sarsotti (53 familias), Santa Rosa de Lima-Estrada (86 familias), y Los Chaqueños (50 familias) poseían un porcentaje aproximado de entre 100 y 50 familias residiendo en condiciones precarias (MLST, 1996). Por otro lado, el 74\% de las familias relevadas no poseían ningún trámite con respecto a su situación dominial, encontrándose asentados sobre suelo declarado de utilidad pública por organismos provinciales o en propiedad de dominio municipal. Del total de estas familias (Cuadro $N^{\circ} 1$ ), el mayor porcentaje -1086 familias, 74\%- no poseía para el año 1996 ningún documento que acredite la posesión de su vivienda; un 5\% -75 familias- disponían de boleto de compraventa, y solo un2\% disponía de escritura -33 familias- y tarjeta de Plan Lote -35 familias-. Es decir, que de las más de 1000 familias censadas por Plan Lote, solo 35 de ellas poseían esta documentación.

\footnotetext{
${ }^{18}$ En los barrios San Agustín II, Yapuyú, La Ranita, Las Lomas, Los Hornos, Villa Hipódromo, Barranquitas Sur, Barranquitas Oeste, Varadero Sarsotti, Chalet, San Lorenzo, Alto Verde, Villa Elsa, San José y Chaqueño. En simultáneo a la construcción de los módulos habitacionales, el PER implicó a su vez equipamientos educativos, centros de Salud, centros comunitarios, jardines maternales y comedores/copa de leche.

19 En contemporáneo tuvieron financiamiento los aportes de la Fundación Interamericana de Estados Unidos, la Organización Wilde Garden y nuevamente de la Cooperativa de viviendas NCIV de Holanda.
} 


\section{Cuadro 1 Condiciones de tenencia de familias que residen en ranchos según el} MLST, Santa Fe, 1996.

\begin{tabular}{|c|c|c|}
\hline Situación Dominial & Cantidad & $\%$ \\
\hline Tiene boleto de compraventa & 75 & 5 \\
\hline Tiene escritura & 33 & 2 \\
\hline Tiene tarjeta Plan Lote & 35 & 2 \\
\hline Otro & 229 & 16 \\
\hline No tiene nada & 1086 & 74 \\
\hline Total & 1475 & 100 \\
\hline
\end{tabular}

Fuente: elaboración propia en base al censo “Datos sociales del sector Marginado" del MLST, 1996.

Para el año 1999, previo a la meta propuesta por esta organización "Santa Fe sin ranchos", esta organización registró 915 planes de Erradicación de Ranchos, de los cuales 765 se encontraban cofinanciados con la Provincia de Santa Fe, 100 cofinanciado con la Unión Europea; y 50 cofinanciado con la Secretaria de Desarrollo de la Nación (Cuadro №2). No obstante, los planes construidos por la propia organización en su mayoría sobre terreno privado, continuaban siendo otorgados a las familias en condiciones precarias de tenencia.

Cuadro 2 Programa de Erradicación de Ranchos: ranchos/planes (cant.) por distrito, Santa Fe, 1989/1999

\begin{tabular}{|c|c|c|c|c|c|c|c|c|c|c|c|c|}
\hline \multirow[b]{3}{*}{$\begin{array}{l}\text { Di } \\
\text { st } \\
\text { rit } \\
\text { O }\end{array}$} & \multirow{3}{*}{$\begin{array}{l}\text { B } \\
\text { ar } \\
\text { ri } \\
\text { os } \\
\text { (c } \\
\text { a } \\
\text { nt } \\
\text {.) }\end{array}$} & \multirow[b]{3}{*}{$\%$} & \multicolumn{10}{|c|}{ Programa de Erradicación de Ranchos } \\
\hline & & & \multicolumn{2}{|c|}{1989} & \multicolumn{2}{|c|}{1995} & \multicolumn{2}{|c|}{1996} & \multicolumn{2}{|c|}{1998} & \multicolumn{2}{|c|}{1999} \\
\hline & & & $\begin{array}{l}\mathrm{b} \\
\mathrm{ar} \\
\mathrm{ri} \\
\text { os }\end{array}$ & $\begin{array}{l}\text { ran } \\
\text { ch } \\
\text { os/ } \\
\text { pla } \\
\text { ne } \\
\text { s }\end{array}$ & $\begin{array}{l}\mathrm{b} \\
\mathrm{ar} \\
\mathrm{ri} \\
\text { os }\end{array}$ & $\begin{array}{c}\text { ran } \\
\text { ch } \\
\text { os/ } \\
\text { pla } \\
\text { ne } \\
\text { s }\end{array}$ & $\begin{array}{l}\mathrm{b} \\
\mathrm{ar} \\
\mathrm{ri} \\
\text { os }\end{array}$ & $\begin{array}{c}\text { ran } \\
\text { ch } \\
\text { os/ } \\
\text { pla } \\
\text { ne } \\
\text { s }\end{array}$ & $\begin{array}{l}\text { b } \\
\text { ar } \\
\text { ri } \\
\text { os }\end{array}$ & $\begin{array}{c}\text { ran } \\
\text { ch } \\
\text { os/ } \\
\text { pla } \\
\text { ne } \\
\text { s }\end{array}$ & $\begin{array}{l}\mathrm{b} \\
\mathrm{ar} \\
\mathrm{ri} \\
\text { os }\end{array}$ & $\begin{array}{c}\text { ran } \\
\text { ch } \\
\text { os/ } \\
\text { pla } \\
\text { ne } \\
\text { s }\end{array}$ \\
\hline SO & 13 & $\begin{array}{l}1 \\
1, \\
1\end{array}$ & 3 & $s / d$ & 3 & 48 & 7 & 224 & 5 & 146 & 4 & 108 \\
\hline
\end{tabular}




\begin{tabular}{|c|c|c|c|c|c|c|c|c|c|c|c|c|}
\hline 0 & 15 & $\begin{array}{l}1 \\
2 \\
8\end{array}$ & 4 & $s / d$ & 4 & 114 & 6 & 241 & 6 & 255 & 6 & 97 \\
\hline NO & 21 & $\begin{array}{l}1 \\
7, \\
9\end{array}$ & 4 & $s / d$ & 5 & 134 & 7 & 227 & 6 & 233 & 4 & 158 \\
\hline $\mathrm{N}$ & 19 & $\begin{array}{l}1 \\
6 \\
2\end{array}$ & 3 & $s / d$ & 2 & 79 & 2 & 114 & 2 & 70 & 3 & 39 \\
\hline NE & 16 & $\begin{array}{l}1 \\
3 \\
7\end{array}$ & - & $s / d$ & - & - & - & - & - & - & - & - \\
\hline E & 18 & $\begin{array}{l}1 \\
5 \\
4\end{array}$ & - & $s / d$ & - & - & 1 & 51 & 2 & 63 & 1 & 15 \\
\hline C & 7 & $\begin{array}{l}5, \\
9\end{array}$ & - & $s / d$ & - & - & - & - & - & - & - & - \\
\hline LC & 8 & $\begin{array}{l}6, \\
8\end{array}$ & 1 & $s / d$ & 1 & 300 & 2 & 276 & 1 & 114 & 1 & 71 \\
\hline Tot & 117 & $\begin{array}{l}1 \\
0 \\
0\end{array}$ & 15 & & 15 & 675 & 25 & 1133 & 22 & 881 & 19 & 488 \\
\hline
\end{tabular}

Nota: Cantidad de módulos habitacionales realizados por el MLST en el marco de Programa de Erradicación de Ranchos por distrito, realizados con financiamiento internacional, nacional, provincial, municipal y de empresas e instituciones privadas. Fuente: elaboración propia en base a documentación obtenida del MLST y del Diario El Litoral para el período.

Para el año 2005 esta organización construyó 7247 Planes de Erradicación de Ranchos; 2480 mejoras habitacionales; 1600 unidades sanitarias; 3000 instalaciones domiciliarias de agua potable; y 350 cuadras de mejorado urbanístico. No obstante, durante el período 2005-2010 no se registra una producción significativa de vivienda y prácticas asistenciales, situación que será condensada hacia el año $2010^{20}$ cuando el MSLT impulsa la Ley de Expropiación de tierras

\footnotetext{
20 Sin embargo, esta situación será revertida desde el año 2012 cuando tuvo lugar la firma del Convenio Marco de "Colaboración y Articulación de Políticas de Hábitat" (2012), en el marco de los Programas Urbanos Integrales, para la construcción de nuevas viviendas en los barrios empobrecidos del oeste y
} 
№13126, conocida como "Ley de expropiación de terrenos privados"21. Paradójicamente, se trata del mismo suelo en donde fueron construidas los primeras viviendas del PER, abarcadas también por Plan Lote pero sin concretar la entrega del dominio a las familias por ninguna de las partes:

“En santa fe, hay 5000 familias que están sobre un terreno privado (...) En el año 1985, el Gobernador lanza el Plan Lote. (...) Lamentablemente se politizo muchísimo, y no se pudo hacer. Y quedaron todos esos barrios con dueños. (...) Entonces en el año 2010 lanza una Ley de Expropiación, en donde dice que el Estado tiene que comprarle la tierra al dueño (...) y después entregárselo al vecino. (...) Todavía no expropió nada el Estado, desde el 2010." (Entrevista Luis Zalazar Al-01 13/03/2017)

En este marco, es importante comprender que se trata de familias asentadas históricamente sobre estos terrenos, a partir de la localización de las viviendas constituidas por esta organización, y tomadas posteriormente por otros programas para su regularización: así como el MSLT construyó primero las viviendas sobre suelo privado, y luego impulso la expropiación de estos terrenos; también participó activamente de las reuniones preliminares a la sanción de la ordenanza del Programa de Regularización Dominial.

\section{La Ley Pierri y regularización dominial, 1994-2007}

La normativa que introduce la regularización dominial en Argentina en general, y en Santa Fe en particular, es la Ley Nacional № 24.374 conocida como "Ley Pierri" 22 sancionada en el año 1994. Esta legislación estableció un régimen de regularización dominial para aquellos ocupantes de inmuebles urbanos que acrediten la posesión pública, pacífica y continua durante tres años, con causa lícita y anterioridad al 1 de enero del año 1992. Sucintamente, la ley instrumentalizó la usucapión como modo de adquirir la propiedad del suelo por su uso y

noroeste. En este marco, desde el año 2012 hasta la fecha, el PER es articulado en forma conjunta entre la organización, aparatos provinciales y municipales; a partir de las modalidades de autoconstrucción con mano de obra en la propia población.

${ }^{21}$ El proyecto de Ley previene la adjudicación a favor del grupo familiar, a título oneroso, pagándose en cuotas mensuales y consecutivas cuyo monto no podrá exceder del $10 \%$ de los ingresos del grupo referido; según señala el Art. $\mathrm{N}^{\circ} 4$. El poder Ejecutivo se hará cargo de los costos de tasas, sellados, planos y mensuras. Se establece que los lotes serán intransferibles por un plazo máximo de 10 años, no pudiendo ser adjudicatario quien sea titular de otra propiedad. También se prevé la cesión a alguna organización no gubernamental o comunitaria con personería jurídica si está asentada en dichos terrenos

22 Bajo este título se conoce a esta ley, por haber sido impulsada por el entonces diputado justicialista Alberto Pierri durante la presidencia de Menem en la década de 1990. 
apropiación por un lapso temporal superior a tres años ${ }^{23}$; siempre y cuando el destino principal sea el de casa habitación única y permanente. En su Art. 3, esta normativa instauró la gratuidad para los beneficiarios del régimen en todos los actos y procedimientos implicados: "En ningún caso constituirán impedimentos, la existencia de deudas tributarias, impositivas o de tasas que recaigan sobre el inmueble, ya sean de jurisdicción nacional, provincial o municipal...". A su vez, estableció un sistema de financiamiento nacional a partir de una contribución única del 1\% del valor fiscal del inmueble, a cargo de los futuros poseedores-beneficiarios.

Desde el año 1994 hasta el 2009, a nivel provincial fueron otorgadas solo 200 escrituras a través de este programa. Sin embargo, esta situación será revertida a partir Decreto № 1178/2009 que le precede, que a partir de su Art. 1 modifica la anterior normativa estableciendo la aplicación de la ley para aquellos ocupantes que acrediten la posición durante tres años con anterioridad al 1을 de enero del año 2009. Desde este momento, la regularización dominial será asumida ahora a nivel provincial por el Ministerio de Desarrollo Social, cuya cartera actuará como autoridad de aplicación de la ley nacional. Serán estos dos instrumentos Ley Pierri y el desbloqueo de esta normativa- los que posibilitarán y acreditarán la operacionalización del PRD a nivel municipal en Santa Fe.

En este contexto, en el año 2007 se realiza el "Diagnóstico de asentamientos informales" en la ciudad. Este relevamiento, hecho en forma conjunta por aparatos municipales y organizaciones sociales, consistió en la elaboración de un registro sobre la localización de los hogares con condiciones precarias de tenencia. Constituyó, en este sentido, un instrumento cartográfico que reunió información hasta entonces dispersa. Las instituciones partícipes de la elaboración de este documento fueron ${ }^{24}$ : i) organismos estatales, entre ellas las ex -Secretarías de Planeamiento Urbano y Subsecretaría de Hábitat y Vivienda-, y la Secretaría de Desarrollo Social junto a las Subsecretarías de Acción Social y Descentralización territorial- del Gobierno de

\footnotetext{
${ }^{23}$ La normativa del código civil estable la usucapión larga por posesión continuada durante 20 años sin justo título y usucapión corta durante 10 años con justo título. En ambos casos, para la prescripción adquisitiva es necesario que el poseedor sea de buena fe.

${ }^{24}$ Concomitantemente, para su elaboración se utilizaron fuentes provenientes de documentos oficiales y artículos en medios periodísticos, entre ellos del CNPHV 2001; la EPV; el Informe final del PROCIFE (informe elaborado luego de la inundación en la ciudad del año 2003); así como bases de datos nacionales, provinciales y locales, y bases legales. Según los datos obtenidos en este informe, aproximadamente 3000 hogares santafesinos residían para ese entonces en viviendas precarias (Premio a la Innovación CIPPEC, 2011).
} 
la Ciudad de Santa Fe; ii) Organizaciones sociales; entre ellas, El MLST'25 y la Asociación Civil CANOA.

De acuerdo a este diagnóstico y según nuestro trabajo de campo, más de 15.000 familias en situación vulnerabilidad social no poseían la titularidad del suelo en donde vivían, en varios casos, desde hacía ya más de treinta años; y otras 1000 familias estaban asentadas en áreas de riesgo hídrico. Para ese entonces, esta situación se extendía a más de 50 barrios del oeste, norte y sector de la costa, que reunían a una población de 70.000 habitantes, lo que representaba aproximadamente un $20 \%$ del total la población de la capital santafesina. De este porcentaje, 10000 familias se encontraban asentadas sobre terrenos de dominio municipal ${ }^{26}$. ¿Qué es lo que compartían en común estos hogares? "Entre los factores determinantes (...) el no ser dueños de la propiedad de la tierra y la vivienda donde vivían"; es decir; la ausencia de la propiedad de la tierra y la vivienda" (Entrevista Sara Lauria, AI-01 12/05/2017).

La elaboración de este diagnóstico, a partir de la construcción de un mapa cartográfico de informalidad, partió de un relevamiento de la situación dominial del suelo con la localización ${ }^{27}$ de los hogares empobrecidos ${ }^{28}$ en condiciones precarias de tenencia, considerando el tipo de dominio del que se trate el suelo: fiscal (propiedad de dominio municipal, provincial o municipal) y/o privados (Mapa $\mathrm{N}^{\circ} 4$ ).

\footnotetext{
${ }^{25}$ En este sentido, en agosto de año 2007 el MSLT presenta un informe ante el Gobierno de la ciudad en cual estiman, para ese año, que cerca de 6000 familias se encontraban residiendo en condiciones sociohabitacionales de empobrecimiento. Según este informe, estas familias "no tenían la titularidad de los terrenos en los que vivían, y requerían la instrumentación de mecanismos que permitan la regularización dominial" (Premio a la Innovación CIPPEC, 2011:8).

${ }^{26}$ Estos datos fueron obtenidos a partir de la entrevista realizada con la directora de ASH, y el Formulario "Premio a la Innovación CIPPEC", óp. Cit.

${ }^{27}$ En este sentido, en el Mapa $\mathrm{N}^{\circ} 10$ se observa la localización espacial histórica sobre el borde oeste de hogares en condiciones precarias de tenencia, principalmente en el suroeste -San Lorenzo, Santa Rosa de Lima, Villa Oculta, Villa del Parque, Barranquitas, San Pantaleón-; algunos sectores del norte de la ciudad -Barrio Chaqueño y Coronel Dorrego-, y el barrio costero Alto Verde. A su vez, en la última década se aprecia la localización de nuevos hogares en estas condiciones sobre el sector costero.

28 Este diagnóstico se elaboró considerando: "la denominación legal o popular del asentamiento, antigüedad, ubicación, tipo de localización, delimitación, calles perimetrales, nomenclatura catastral, cantidad de hogares y parcelas, densidad de población, población con NBI, situación dominial de la tierra, infraestructura urbana (energía eléctrica, alumbrado público, agua potable, red cloacal, desagües, pavimento, recolección de residuos; existencia o no de planos de mensura, subdivisión o loteo; variables ambientales -riesgo hídrico, actividades contaminantes, basurales, aguas servidas en la vía pública, relleno sanitario, cavas, etc.-; accesibilidad y conectividad a escala barrial y urbana; equipamientos sociales y comunitarios; etc.)." (Premio a la Innovación CIPPEC, 2011:8).
} 
Mapa 4 Espacialización histórica en donde residen hogares con condiciones precarias de tenencia, Santa Fe, 1985- 2007.

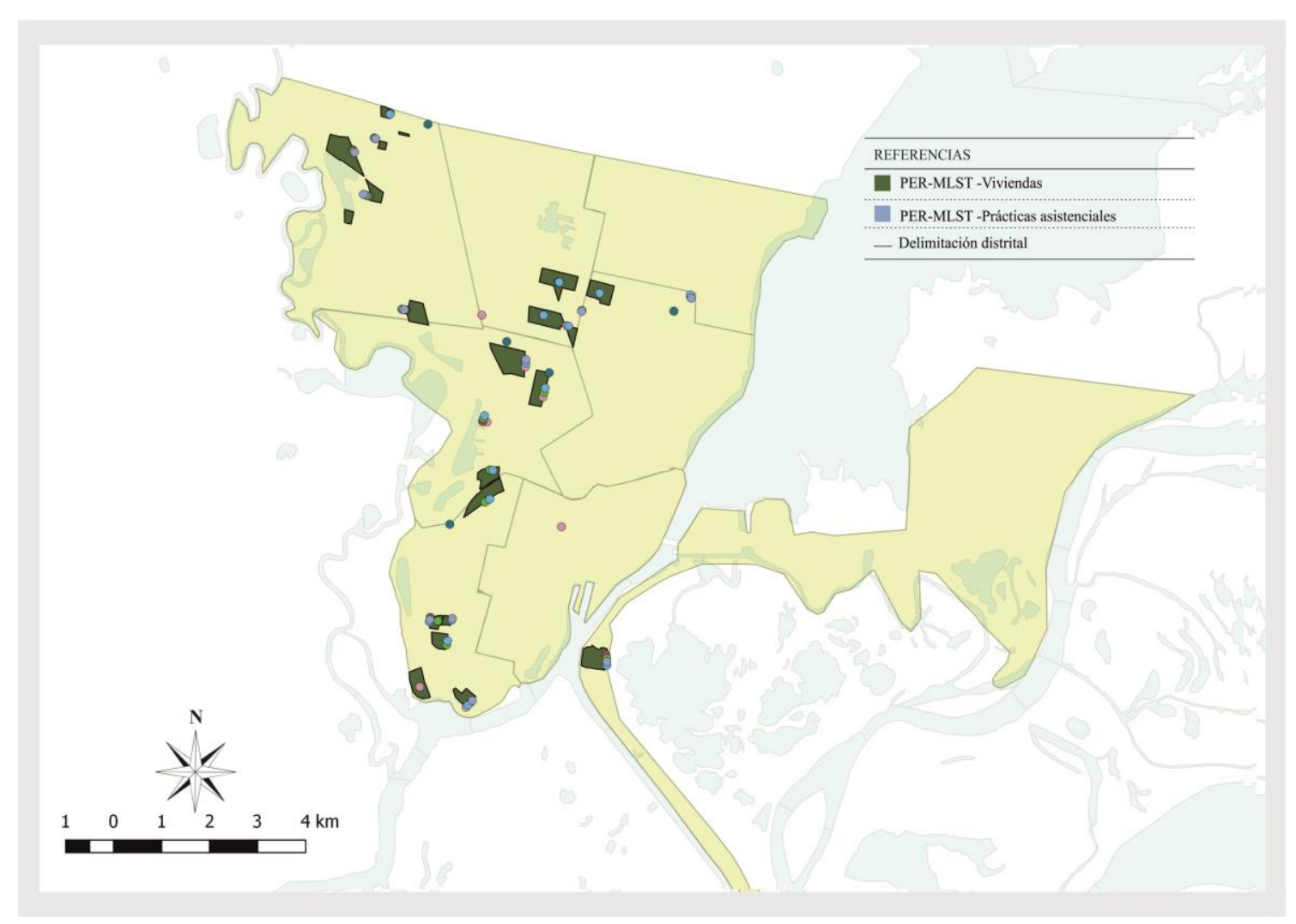

Fuente: elaboración propia realizada según nuestro trabajo de campo en base al "Diagnóstico urbano de asentamientos informales" realizado por la Municipalidad de la Ciudad de Santa Fe -Agencia Santa Fe Hábitat, 2007.

En este contexto, del total de la población registrada para el año 2007 en la ciudad de Santa $\mathrm{Fe}$, un 38,5\% residían en viviendas en donde sus lotes - en forma parcial o total- no se encentraban regularizados dominialmente -Cuadro $\mathrm{N}^{0}$ 1-. Esto implicaba una población aproximada de 70000 habitantes, es decir, un 15\% del total de la población santafesina para ese año.

Cuadro 1 Población y barrios según tipo de tenencia del suelo (cantidad y \%), Santa Fe, 2007

\begin{tabular}{|l|l|l|c|}
\hline & \multicolumn{2}{|c|}{ Tipo de tenencia } & Total \\
\hline En condiciones precarias de tenencia & Con & Santa Fe \\
\hline
\end{tabular}




\begin{tabular}{|c|c|c|c|}
\hline & & tenencia del suelo & \\
\hline Barrios & 45 & 72 & 117 \\
\hline & $38,50 \%$ & $61,50 \%$ & $100 \%$ \\
\hline Población & 70000 & 421208 & 491208 \\
\hline & $15 \%$ & $85 \%$ & $100 \%$ \\
\hline
\end{tabular}

Fuente: elaboración propia en base a datos de MCSF-BCSF-Agencia Santa Fe Hábitat - MCSF en base al Diagnóstico realizado por esta institución en 2007. También se incorporaron datos poblacionales del IPEC correspondientes al tercer trimestre de 2007.

Del total de hogares en condiciones precarias de tenencia (Cuadro N² 2), la mitad -51\%.se localizaba en suelo de dominio municipal, y abarcaba aproximada de 10000 hogares. El 29\% de los hogares residían en barrios en donde se presenciaba más de un dominio en el suelo, y un $16 \%$ se asentaba sobre terreno de dominio privado. Un menor porcentaje -4\%-residía sobre suelo de dominio provincial o nacional. De este total, 23 barrios se localizaban sobre suelo en zona de riesgo hídrico, y en 6 barrios residían hogares asentados sobre la vía de ferrocarril.

\section{Cuadro 2 Hogares y barrios en condiciones precarias de tenencia del suelo} (cantidad y \%): por tipo de dominio, Santa Fe, 2007

\begin{tabular}{|c|c|c|c|c|c|c|c|}
\hline & \multicolumn{7}{|c|}{ Sin tenencia de suelo } \\
\hline & \multicolumn{5}{|c|}{ Dominio de suelo } & \multicolumn{2}{|c|}{ A relocalizar } \\
\hline & municipal & provincial & nacional & privada & $\begin{array}{c}\text { más de un } \\
\text { dominio }\end{array}$ & $\begin{array}{c}\text { en zona de } \\
\text { riesgo } \\
\text { hídrico }\end{array}$ & $\begin{array}{l}\text { sobre vía } \\
\text { ferrocarril }\end{array}$ \\
\hline \multirow[t]{2}{*}{ Barrios } & 23 & 1 & 1 & 7 & 13 & 23 & 6 \\
\hline & $51 \%$ & $2 \%$ & $2 \%$ & $16 \%$ & $29 \%$ & $51 \%$ & $15 \%$ \\
\hline \multirow[t]{2}{*}{ Hogares } & 10016 & 1467 & 490 & 1832 & $s / d$ & 1423 & 250 \\
\hline & $72 \%$ & $11 \%$ & $4 \%$ & $13 \%$ & - & $85,1 \%$ & $14,9 \%$ \\
\hline
\end{tabular}

Fuente: elaboración propia realizada según nuestro trabajo de campo en base al "Diagnóstico urbano de asentamientos informales" realizado por la Municipalidad de la Ciudad de Santa Fe -Agencia Santa Fe 
Hábitat, 2007. También se incorporaron datos poblacionales del IPEC correspondientes al tercer trimestre de 2007.

De los 14869 hogares registrados sin la tenencia del suelo, más de la mitad -56,7\%, 8430 hogares - disponían planos de mensura, subdivisión y loteo, estando el mayor porcentaje localizado sobre dominio municipal. Estos hogares se encontraban principalmente hacia el suroeste de la ciudad, y en menor escala hacia el noroeste. Los hogares localizados en área de riesgo hídrico, a relocalizar por el gobierno, se localizaban mayoritariamente sobre la zona de la costa, comprendiendo Alto Verde, y hacia el norte. Del total de estos hogares, el 43,4\% no disponía de esta documentación, y se localizaban en su mayoría sobre suelo de dominio municipal o privado (Cuadro $N^{\circ} 5$ ). No obstante, las localizaciones mencionadas coinciden con la ubicación histórica de hogares empobrecidos en donde se instrumentalizo anteriormente Plan Lote y el PER.

Cuadro 5 Hogares con y sin planos de mensura, subdivisión y loteo (cantidad y $\%)$, Santa Fe, 2007

\begin{tabular}{|c|c|c|c|c|c|c|c|}
\hline & \multirow{2}{*}{ Total } & \multicolumn{4}{|c|}{$\begin{array}{l}\text { Planos de mensura, subdivisión y } \\
\text { loteo }\end{array}$} & \multirow{2}{*}{$\begin{array}{l}\text { Hogares a } \\
\text { relocalizar }\end{array}$} & \multirow{2}{*}{$\%$} \\
\hline & & $\begin{array}{l}\text { Lotes con } \\
\text { planos }\end{array}$ & $\%$ & $\begin{array}{l}\text { Lotes sin } \\
\text { planos }\end{array}$ & $\%$ & & \\
\hline $\begin{array}{l}\text { Hogares en terrenos } \\
\text { municipales }\end{array}$ & 10016 & 7976 & 53,6 & 2040 & 13,7 & $s / d$ & \\
\hline $\begin{array}{l}\text { Hogares en terrenos } \\
\text { provinciales }\end{array}$ & 1467 & - & & 1467 & 9,9 & $s / d$ & \\
\hline $\begin{array}{l}\text { Hogares en terrenos } \\
\text { nacionales }\end{array}$ & 490 & 454 & 3,1 & 1100 & 7,4 & $s / d$ & \\
\hline $\begin{array}{l}\text { Hogares en terrenos } \\
\text { privados }\end{array}$ & 1832 & - & & 1832 & 12,3 & $s / d$ & \\
\hline Total & 14869 & 8430 & 56,7 & 6439 & 43,3 & & \\
\hline $\begin{array}{l}\text { Hogares en zona de } \\
\text { riesgo hídrico }\end{array}$ & 1423 & $s / d$ & & $s / d$ & & 1423 & 85,1 \\
\hline $\begin{array}{l}\text { Hogares sobre vía } \\
\text { ferrocarril }\end{array}$ & 250 & $s / d$ & & $s / d$ & & 250 & 14,9 \\
\hline Total & 1673 & & & & & & \\
\hline
\end{tabular}


Fuente: elaboración propia realizada según nuestro trabajo de campo en base al "Diagnóstico urbano de asentamientos informales" realizado por la Municipalidad de la Ciudad de Santa Fe -

Agencia Santa Fe Hábitat, 2007.

En este contexto, y retomando el Plan Lote, si en el año 1985 fueron relevados en la ciudad 8 barrios en donde habitaban hogares en condiciones precarias de tenencia; para el año 1995, este porcentaje se incrementó a 21 barrios. Esta cuestión indicó que aproximadamente un 30\% de los hogares no poseían documentación que acredite el dominio del suelo, situación que permite inferir desplazamientos residenciales considerando dos posibles tendencias: que sean las mismas familias las que residen sobre ese suelo, a partir de modificaciones en el grupo familiar; o bien, que se trate de la permanencia física de las viviendas sobre esos terrenos, siendo los hogares los que se desplazan. Asimismo, para el año 2007, periodo en donde se realizó el diagnostico de asentamientos informales, el porcentaje antes visto se incrementó aproximadamente un $10 \%$.

\section{El programa de Regularización Dominial, 2009}

La normativa que dará lugar a la operatoria de regularización de la tenencia de suelo en la ciudad de Santa Fe es la Ordenanza N 11631 conocida como "Legalización masiva de la tenencia de la tierra" (Mapa $N^{\circ}$ 5). Esta normativa, sancionada en el año 2009, fue instrumentalizada en los ocho distritos de la ciudad, priorizando:

"la intervención en aquellos barrios o asentamientos informales donde viven familias o grupos sociales de escasos recursos que no poseen la titularidad de los terrenos en los que viven"; (...) "familias que se encuentran asentadas en áreas de vulnerabilidad hídrica". (Ordenanza $\mathrm{N}^{\circ}$ 11631) 


\section{Mapa 5 Programa de Regularización Dominial: localización espacial de hogares} con condiciones precarias de tenencia, Santa Fe, 2007.

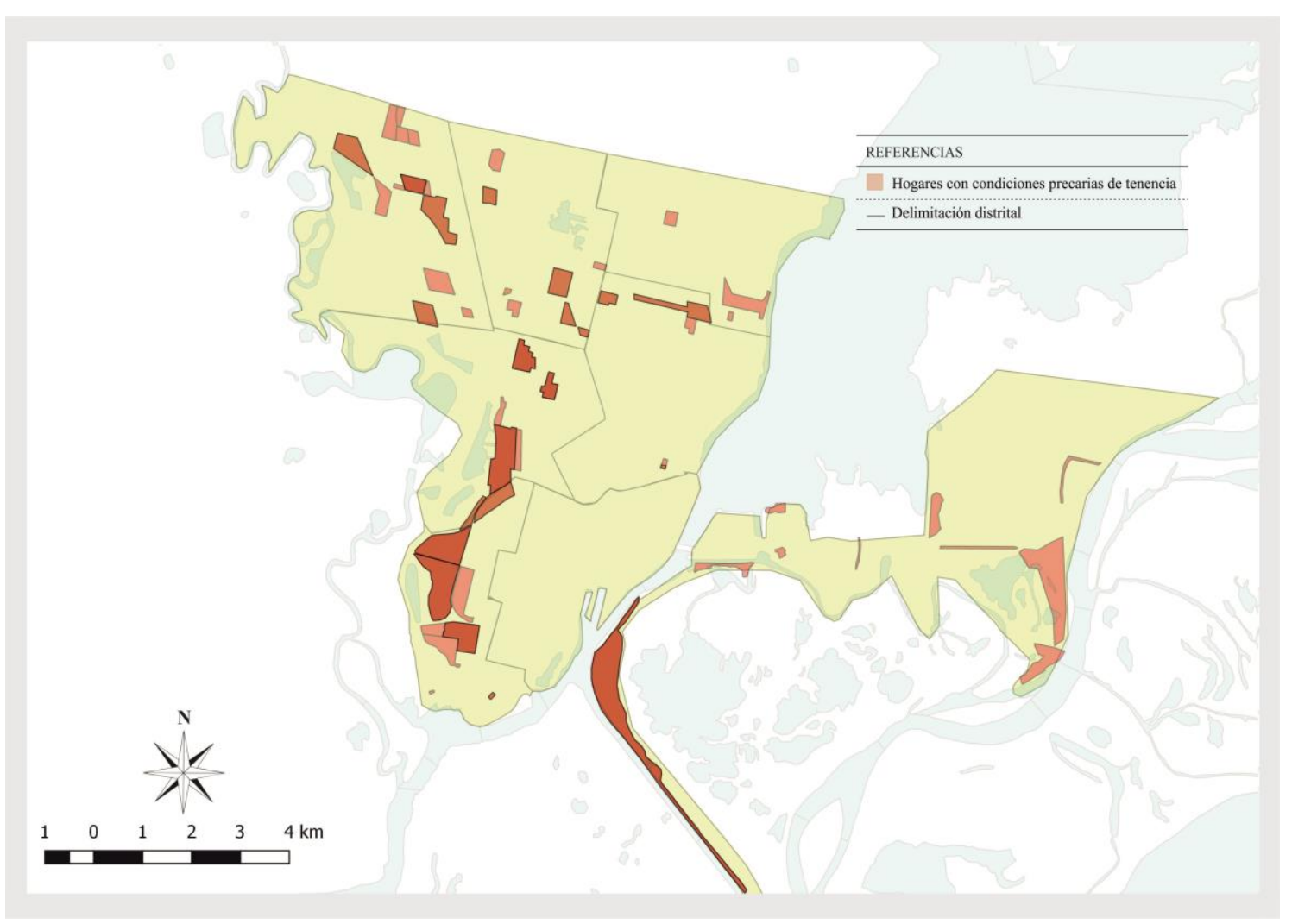

Fuente: elaboración propia realizada según nuestro trabajo de campo en base al "Diagnóstico urbano de asentamientos informales" realizado por la Municipalidad de la Ciudad de Santa Fe -Agencia Santa Fe Hábitat, 2007.

Si bien la ordenanza que reglamento el PRD en la ciudad data del año 2009, será en el 2011, a través de la Ordenanza N 11836 y sobre la base del Ex Instituto Municipal de la Vivienda -Ordenanza N 10382- cuando se crea "Santa Fe Hábitat: Agencia para el desarrollo social y urbano"29. Esta agencia, constituida como un ente autárquico municipal, tiene como misión la definición de políticas y estrategias relacionadas al hábitat, en materia de gestión y producción; siendo una de sus principales funciones la coordinación, programación y ejecución del Plan de Regularización Dominial. En este sentido, el Art. $N^{\circ} 1$ que da lugar a dicha concreción establece como fin:

\footnotetext{
${ }^{29}$ Este organismo viene a suceder al anterior Instituto Municipal de la Vivienda. Sobre esta base se creó la agencia como ente autárquico municipal, modificando y actualizando fundamentalmente los objetivos, funciones y misiones del anterior.
} 
"promover el desarrollo y articulación de las políticas orientadas al mejoramiento integral de los asentamientos urbanos informales, basadas en una concepción del hábitat como espacio social para la construcción de ciudadanía, en el marco de un modelo de inclusión e integración socio física con mejora en la calidad de vida y en el pleno derecho a la ciudad" (Premio a la Innovación CIPPEC, 2011:1).

En este marco, el programa de regularización dominial apuntó a:

"mejorar la calidad de vida y facilitar el acceso a la propiedad de la tierra y la vivienda a familias en situación de pobreza y marginalidad, que no tenían la titularidad de los terrenos en los que vivían, en la mayoría de los casos por más de treinta años". (ASF, 2011:1)

En este sentido, el Art. 3o de la presente ordenanza propone: “...otorgar seguridad jurídica y legal mediante el otorgamiento de la escritura traslativa de dominio a favor de los grupos familiares que habiten en terrenos municipales...". Asimismo, el Art. 4o enuncia que: "garantizar el uso social del suelo, dando prioridad y disponiendo los medios necesarios para que la población de escasos recursos pueda hacer efectivo el derecho de acceso a la titularidad dominial de la tierra.....". Sin embargo, esta ordenanza sentó sus bases sobre una serie de normativas aprobadas décadas atrás a instrumentalizarse en hogares que para ese entonces residían con condiciones precarias de tenencia ${ }^{30}$.

En lo específico para el caso santafesino, esta política dispuso:

a) la gratuidad de todos los trámites de escrituración para las familias involucradas, a partir de la constitución de un Fondo Especial para la cobertura de los gastos de mensura, subdivisión, loteo y escrituración;

b) la incorporación de la Constancia de Ocupación, instrumento previo a la entrega traslativa de dominio, el cual tuvo como fin el reconocimiento y la acreditación por parte de aparatos estatales a las familias sobre la posesión de la tierra en donde las mismas residen. Constituye, según la normativa de este programa, "el primer paso hacia la entrega de la escritura traslativa de dominio a favor de sus legítimos propietarios";

\footnotetext{
${ }^{30}$ Entre ellas, la Ordenanza № 8240 "Régimen general de loteos de terrenos municipales" del año 1982, cuyo objeto fue la venta directa en forma privada a grupos familiares o personas de escasos recursos de inmuebles de propiedad municipal; y tuvo como modificatoria a la Ordenanza № 9159 de año 1989 de "Eximición a favor del comprador" disponiéndose la eximición del pago de lote al comprador por cinco años; y la Ordenanza № 10.192, sancionada en el año 1997 de "Rescisión de ventas directas de lotes de terrenos municipales". A su vez, la mencionada Ley Pierri del año 1994 a nivel nacional, y la Ordenanza № 10382 de "Creación del Instituto Municipal de Vivienda" del año 1998.
} 
c) a su vez, establece la aplicación del Avaluó Fiscal y Social para el valor de los terrenos a regularizar -de modo similar al Plan Lote-, a partir de la creación del fondo destinado a solventar los gastos implicados en este proceso.

En consonancia, esta política de regularización contempla la instrumentalización de relocalizaciones de familias "asentadas en sectores de riesgo hídrico o en espacios públicos, en un proceso que incluye la construcción de módulos habitacionales mínimos y el acceso a la tierra" (Gobierno de la Ciudad de Santa Fe, s/f). En este contexto, apreciamos como los programas instrumentalizados décadas atrás en Santa Fe, sientan las bases para la instrumentalización del programa de regularización dominial; así como también comprenden los mismos sectores urbanos a intervenir (Mapa $\mathrm{N}^{\circ} 6$ ).

\section{Mapa 6 Espacialización de prácticas asistenciales del MLST y hogares con condiciones precarias de tenencia, Santa Fe, 1985-2010.}

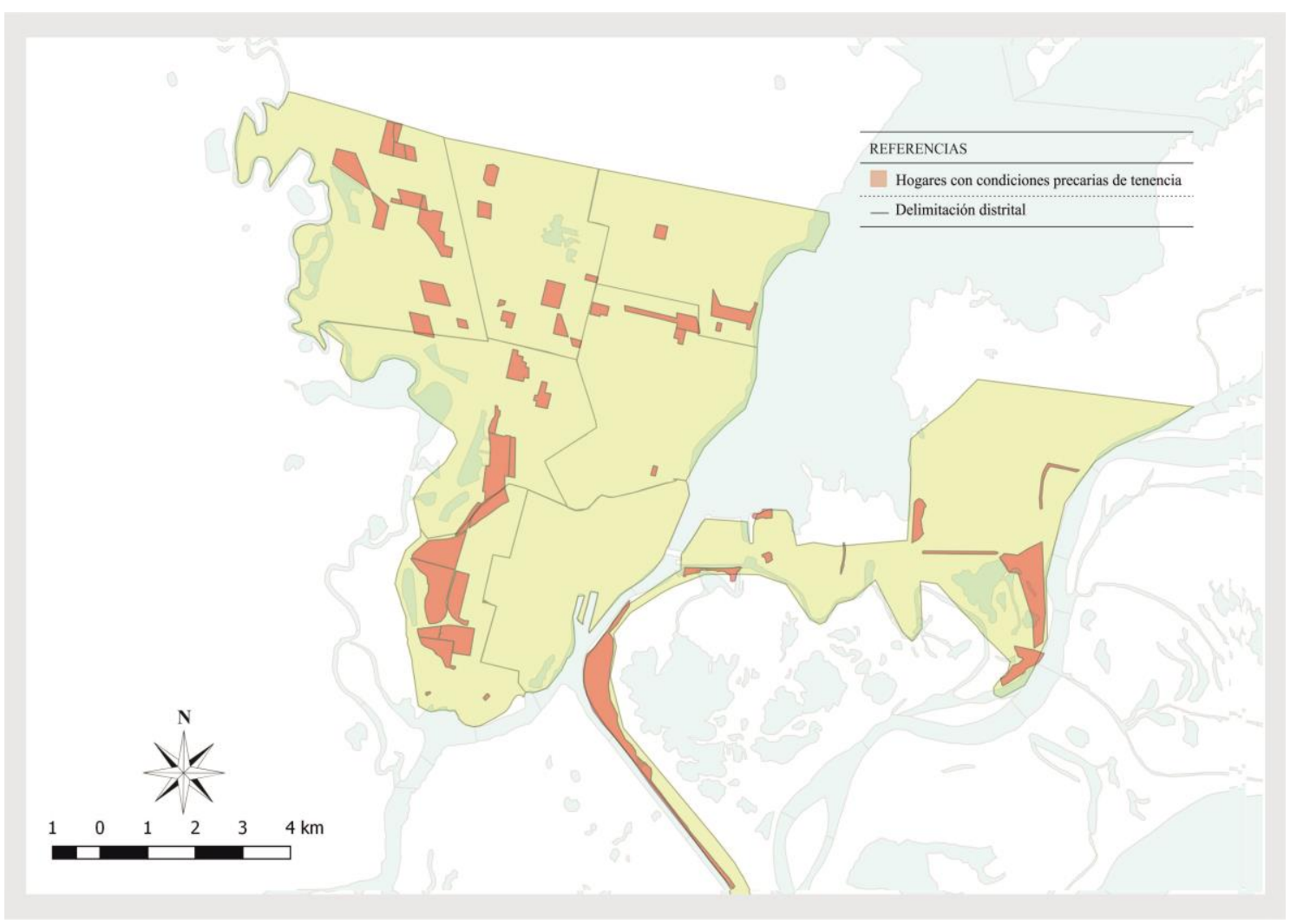

Fuente: elaboración propia según nuestro trabajo de campo en base al "Diagnóstico urbano de asentamientos informales" realizado por la Municipalidad de la Ciudad de Santa Fe -Agencia Santa Fe Hábitat, 2007, y documentación obtenida del MLST. 
En cuanto a los resultados alcanzados por este programa, predomina la regularización sobre terrenos municipales, principalmente hacia el suroeste y norte de la ciudad; pero no otorgando principalmente escrituras de dominio, sino otros tipos de instrumentos que política intervienen en este proceso (ASF, 2011:12):

-Constancia de Ocupación: acredita la posesión de la tierra y constituye el documento necesario para acceder al proceso de regularización, dado que otorga exclusividad de derecho de adjudicación a su poseedor;

-Certificado de Cancelación de Deuda: cancela el compromiso de pago de cuotas pendientes en terrenos que hayan sido afectados por la inundación 2003, siempre que el titular del boleto de compra-venta continúe viviendo en el lugar, habilitando a iniciar los trámites de escrituración a su nombre;

-Escritura traslativa de dominio: formaliza legalmente la adjudicación en venta y transferencia del dominio del inmueble.

Hasta el año 2017, se han entregado 3.893 escrituras de dominio. Si comparamos este total desde el inicio de programa, vemos como en el periodo 2008-2011 solo se entregaron 201 escrituras; priorizando en ese momento la entrega de constancia de ocupación a los hogares. A su vez, la entrega de documentos de constatación de aptitud para escriturar u boletos de compraventa; en todos los casos son mayores a la cantidad de escrituras otorgadas. No obstante, a partir del año 2012 observamos un salto cuantitativo, siendo más de 2000 las escrituras otorgadas. Empero, vemos nuevamente un retroceso dado que para el 2017 solo se incrementaron la entrega de 1000 nuevas escrituras. Nuevamente, predomina para este período la entrega de constancias de ocupación.

Cuadro 11 Alcances del Programa de Regularización Dominial, Santa Fe, 20082017

\begin{tabular}{|c|c|c|c|c|c|c|c|c|c|}
\hline \multicolumn{10}{|c|}{ Hogares } \\
\hline A & Par & Sin & En & Con & Con & Con & Con & Con & Con \\
$\tilde{n}$ & cial & ten & ZRH - & cons & certif. & cons & boleto & escri & plano \\
o & & enci & a & tan. & cance & t. de & de & tura & s de \\
& & a & reloc & de & lación & aptit & compr & s & subdi \\
& & del & alizar & ocup & de & ud & aventa & & visión \\
& & suel & - & ació & deud & para & & & , \\
& & & & & & & & & \\
\end{tabular}




\begin{tabular}{|c|c|c|c|c|c|c|c|c|c|}
\hline & & 0 & & $n$ & $a$ & $\begin{array}{c}\text { escri } \\
\text { tura } \\
r\end{array}$ & & & $\begin{array}{c}\text { Mens } \\
\cdot y \\
\text { loteo }\end{array}$ \\
\hline $\begin{array}{c}200 \\
8\end{array}$ & & 15478 & 1673 & 152 & 50 & 0 & 75 & 114 & $s / d$ \\
\hline $\begin{array}{c}200 \\
9\end{array}$ & & $s / d$ & $s / d$ & 928 & 219 & 33 & 0 & 0 & $s / d$ \\
\hline $\begin{array}{c}201 \\
0\end{array}$ & & $s / d$ & $s / d$ & 885 & 118 & 137 & 0 & 18 & $s / d$ \\
\hline \multirow{2}{*}{$\begin{array}{c}201 \\
1\end{array}$} & & $s / d$ & $s / d$ & 322 & 8 & 16 & 274 & 69 & $s / d$ \\
\hline & $\begin{array}{l}2008 / \\
2011\end{array}$ & $s / d$ & $s / d$ & 2.287 & 395 & 186 & 349 & 201 & \\
\hline \multirow{2}{*}{$\begin{array}{c}201 \\
2\end{array}$} & & & & 848 & $s / d$ & $s / d$ & 195 & 98 & 420 \\
\hline & $\begin{array}{l}2008 / \\
2012\end{array}$ & $s / d$ & $s / d$ & 4500 & & & 1528 & 2157 & 1500 \\
\hline $\begin{array}{c}201 \\
3\end{array}$ & & & & 0 & $s / d$ & $s / d$ & 209 & 386 & $s / d$ \\
\hline \multirow{2}{*}{$\begin{array}{c}201 \\
4\end{array}$} & & & & 0 & $s / d$ & $s / d$ & 164 & 386 & $s / d$ \\
\hline & $\begin{array}{l}2008 / \\
2014\end{array}$ & $s / d$ & $s / d$ & 4500 & & & 1901 & 2729 & \\
\hline \multirow{2}{*}{$\begin{array}{c}201 \\
5\end{array}$} & & & & & & 384 & & 332 & 303 \\
\hline & $\begin{array}{l}2008 / \\
2015\end{array}$ & $s / d$ & $s / d$ & $s / d$ & & $s / d$ & & 3.061 & \\
\hline \multirow[t]{2}{*}{$\begin{array}{c}201 \\
6\end{array}$} & & & & & & & & & \\
\hline & $\begin{array}{l}2008 / \\
2016\end{array}$ & $s / d$ & $s / d$ & 4500 & $s / d$ & $s / d$ & 2000 & 3768 & $s / d$ \\
\hline 201 & & & & & & & & & \\
\hline
\end{tabular}




\begin{tabular}{|c|c|c|c|c|c|c|c|c|c|}
\hline 7 & & & & & & & & & \\
\hline & $\begin{array}{c}2008 / \\
2017\end{array}$ & 11232 & 1000 & $s / d$ & $s / d$ & $s / d$ & $s / d$ & 3.893 & $s / d$ \\
\hline
\end{tabular}

Fuente: elaboración propia realizada según nuestro trabajo de campo en base al "Diagnóstico urbano de asentamientos informales" realizado por la Municipalidad de la Ciudad de Santa Fe -Agencia Santa Fe Hábitat, 2007.

De esta manera, observamos un predominio de entrega de documentos que no avalan la propiedad, sino que más bien refuerzan la ideología de la propiedad como meta ultima; cuestión que implica que las familias se vean forzadas a atravesar sucesivas instancias, que van desde los actos públicos y de propaganda de entrega de documentos, acarreando con los años la espera e incertidumbre sobre el título de propiedad:

“El trabajo comenzó con la 'verificación de ocupación': por barrio se organizó un relevamiento lote a lote de las familias que viven en terrenos municipales (...) en este marco, los vecinos que adquirieron un terreno municipal mediante un plan de pago en cuotas hasta abril de 2003 que fueron afectados por la inundación y continúan viviendo en el lugar, recibirán un 'certificado de cancelación de deuda'. Aquellos que actualmente viven en terrenos municipales recibirán una 'constancia de ocupación'. Con esta constancia, aquellas familias de escasos recursos, que no cuenten con otra propiedad y acrediten tiempo de residencia, podrán iniciar los trámites para la compra del lote. La Municipalidad determinará el precio de venta del lote y el vecino podrá elegir un plan de pagos acorde a sus posibilidades económicas. Una vez elegido el plan de pagos se firma el boleto de compra-venta de lote. ( ) Finalmente, una vez concluido el plan de pagos o con el certificado de cancelación de deuda, se podrán iniciar los trámites para escriturar el terreno a nombre del adjudicatario". (Periódico 30 Días, octubre 2008, publicación mensual)

Esto nos permite inferir, en este sentido, la instrumentalización ideológica de una política que promulga, avala y defiende la propiedad privada, pero que cuantitativamente no condice con los resultados.

\section{Los programas urbanos integrales, 2012}

Mediante el Decreto No 2424 “Creación Programa Urbano Integral del Oeste y del Noreste" del año 2011, comienzan a instrumentalizarse a principios del año 2012 los PUI en la ciudad. Estos programas son considerados por el Gobierno de Santa Fe como mecanismos de 
gestión e intervención cuyo destino de aplicación son sectores urbanos complejos, signados por carencias físicas y sociales (Gobierno de Santa Fe, 2012). Tienen dependencia directa del Intendente de la ciudad y son transversales a todas las secretarías municipales. En los discursivo, parten de tres ejes: i) la dimensión física, en donde se interviene en la construcción y mejoramiento del espacio social, movilidad, dotación de infraestructuras y equipamientos, y construcción de viviendas, entre otros; ii) la dimensión social, en donde se articulan a través de convenios, el trabajo conjunto entre aparatos estatales, organizaciones e instituciones de la sociedad civil, agencias de cooperación nacionales e internacionales, empresas privadas y la población implicada; y iii) la dimensión institucional, a partir de los principios considerados como de descentralización municipal, a saber, territorio, comunidad, fondos públicos y planeación integrada.

A su vez, toman como antecedentes otros programas, buscando "adaptar experiencias exitosas de intervención urbana integral llevadas adelante en Sudamérica" (Decreto № 2424, 2011:1). Entre ellas, las experiencias de PROMEBA en Argentina y el antecedente de los PUI en Medellín. En la ciudad de Santa Fe son los dos los programas integrales operacionalizados (Mapa $\left.N^{\circ} 7\right)$ :

- PUI, que interviene en dos sectores urbanos: el PUI del Noreste, que comprende a las familias que residen en los barrios Coronel Dorrego, Nueva Esperanza, Guadalupe Oeste, Guadalupe Noreste y Guadalupe Central, entre otras zonas; y el PUI del Oeste, que abarca a las familias de los barrios Villa Oculta, Villa del Parque, Barranquitas Sur, Barranquitas Oeste y Pro Mejoras Barranquitas;

- PROMEBA, que articula a través de nación la realización de proyectos integrales en los barrios Santa Rosa de Lima, 12 de Octubre y San Lorenzo, entre otros. Sin embargo, este programa se compone de cuatro préstamos e inicialmente abarco los barrios Loyola y Abasto en el año 1997, y actualmente desde inicios del 2017 incluye Villa Oculta. 
Mapa 7 Programas urbanos integrales de mejoramiento barrial: localización espacial de hogares con condiciones precarias de tenencia, Santa Fe, 2012.

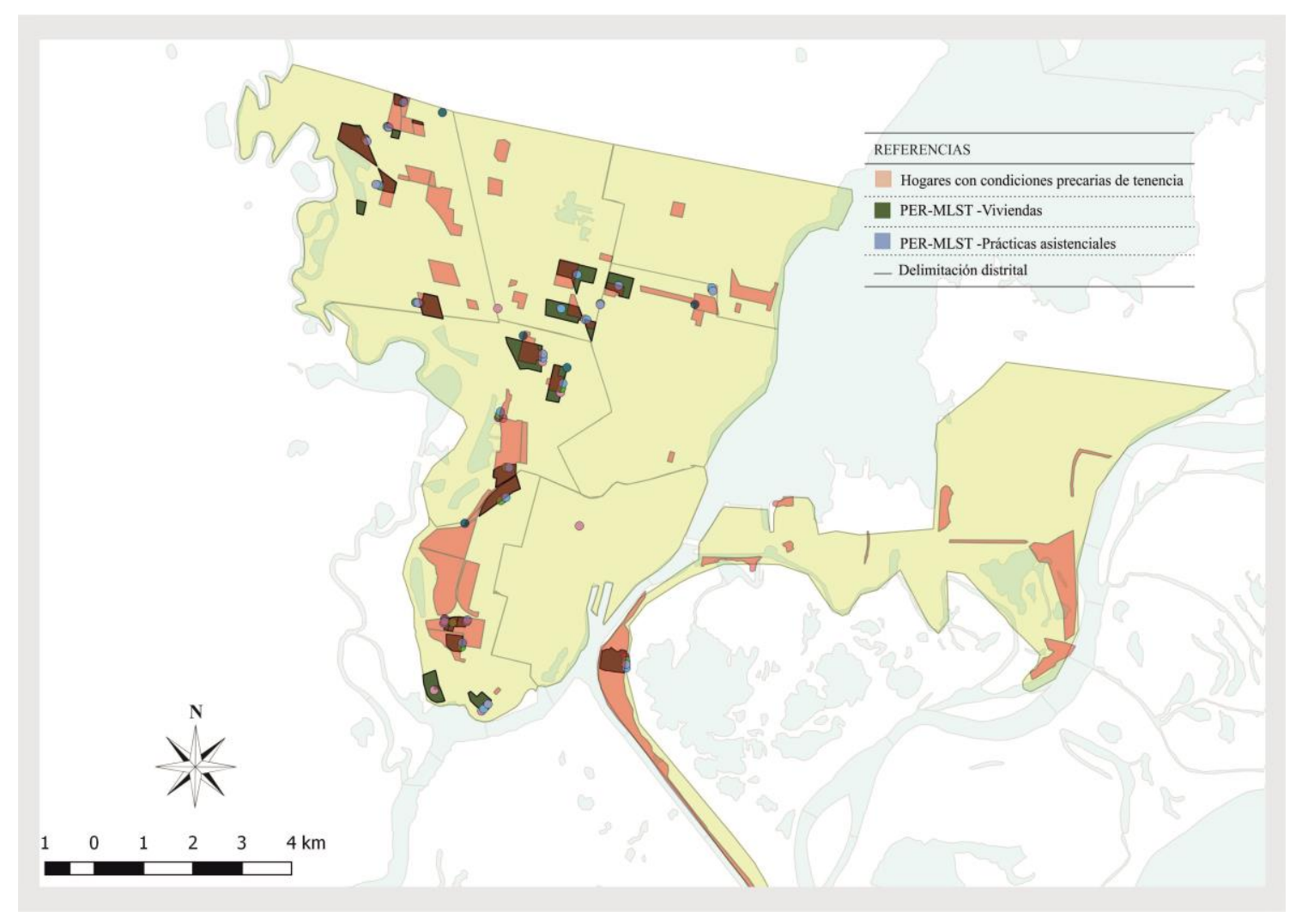

Fuente: elaboración propia realizada según nuestro trabajo de campo en base Programa de Mejoramiento Barrial -PROMEBA-, 1997, el "Diagnóstico urbano de asentamientos informales" realizado por la Municipalidad de la Ciudad de Santa Fe -Agencia Santa Fe Hábitat, 2007, y los Programas Urbanos Integrales del Oeste y Noreste, 2012.

Los primeros programas de este tipo corresponden a los PROMEBA y se ejecutaron a través de préstamos financieros del BID desde hace dos décadas. Su operacionalizaron se enmarca, fundamentalmente, en algunos barrios empobrecidos del Oeste. Los PUI, si bien incluyen los barrios señalados anteriormente del Oeste no involucrados en PROMEBA, incorporan su vez algunos sectores del noreste empobrecido de la ciudad (Cuadro $N^{\circ} 7$ ). 
Cuadro 7 Programas integrales de mejoramiento barrial: años, préstamos, proyectos y población implicada, Santa Fe. 2007-2017.

\begin{tabular}{|c|c|c|c|c|c|c|c|}
\hline $\begin{array}{c}\text { Progra } \\
\text { ma }\end{array}$ & & $\begin{array}{c}\text { Añ } \\
\text { O }\end{array}$ & Barrios & $\begin{array}{c}\text { Présta } \\
\text { mo }\end{array}$ & $\begin{array}{l}\text { Organis } \\
\text { mos } \\
\text { locales }\end{array}$ & Proyecto & $\begin{array}{l}\text { Poblaci } \\
\text { ón } \\
\text { Implica } \\
\text { da }\end{array}$ \\
\hline \multirow{5}{*}{$\begin{array}{c}\text { PROMEB } \\
\text { A }\end{array}$} & $\begin{array}{c}\text { Prome } \\
\text { bal }\end{array}$ & 1997 & $\begin{array}{l}\text { Loyola, } \\
\text { Abasto }\end{array}$ & BID & $s / d$ & $s / d$ & $s / d$ \\
\hline & $\begin{array}{c}\text { Prome } \\
\text { ba II }\end{array}$ & 2007 & \multirow{3}{*}{$\begin{array}{l}\text { Santa } \\
\text { Rosa de } \\
\text { Lima, } \\
\text { Estrada, } \\
12 \text { de } \\
\text { octubre }\end{array}$} & BID & $\begin{array}{c}\text { Nación -por } \\
\text { Promeba } \\
\text { (64\%) - y } \\
\text { Municipio } \\
(36 \%)\end{array}$ & $\begin{array}{l}1^{\circ} \text { Et. red } \\
\text { desagües } \\
\text { cloacales }\end{array}$ & 1100 flias. \\
\hline & & & & BID & & $\begin{array}{l}\text { Alumbrado } \\
\text { público }\end{array}$ & $\begin{array}{c}17000 \\
\text { hab. }\end{array}$ \\
\hline & $\begin{array}{c}\text { Prome } \\
\text { ba III }\end{array}$ & 2012 & & BID & $\begin{array}{c}\text { Nación por } \\
\text { Promeba } \\
(63 \%) \text { y } \\
\text { Municipio } \\
(37 \%)\end{array}$ & $\begin{array}{l}\text { Extensión de } \\
\text { la red de } \\
\text { desagües } \\
\text { cloacales }\end{array}$ & 5000 hab. \\
\hline & $\begin{array}{c}\text { Prome } \\
\text { ba VI }\end{array}$ & 2017 & $\begin{array}{c}\text { Santa } \\
\text { Rosa de } \\
\text { Lima, Villa } \\
\text { Oculta }\end{array}$ & BID & $\begin{array}{l}\text { Nación por } \\
\text { Promeba } \\
(76 \%) \text { y } \\
\text { Municipio } \\
(24 \%)\end{array}$ & $\begin{array}{c}\text { Cordón } \\
\text { cuneta, } \\
\text { extensión } \\
\text { desagües, } \\
\text { red de agua } \\
\text { y cloaca, } \\
\text { pavimento } \\
\text { de } \\
\text { hormigón, } \\
\text { Mediateca }\end{array}$ & $\begin{array}{c}17000 \\
\text { hab. }\end{array}$ \\
\hline \multirow{6}{*}{ PUI } & \multirow{6}{*}{$\begin{array}{c}\text { PUI } \\
\text { Oeste }\end{array}$} & \multirow{5}{*}{2012} & $\begin{array}{l}\text { Villa del } \\
\text { Parque }\end{array}$ & & \multirow{5}{*}{$\begin{array}{l}\text { Nación y } \\
\text { Municipio }\end{array}$} & \multirow{5}{*}{$\begin{array}{c}\text { saneamient } \\
\text { o, } \\
\text { generación } \\
\text { de suelo } \\
\text { urbano y } \\
\text { equipamient } \\
\text { os, creación } \\
\text { de espacios } \\
\text { públicos, y } \\
\text { construcción } \\
\text { de viviendas }\end{array}$} & $S / d$ \\
\hline & & & $\begin{array}{l}\text { Villa } \\
\text { Oculta }\end{array}$ & & & & \\
\hline & & & $\begin{array}{l}\text { Barranqui } \\
\text { tas Oeste }\end{array}$ & & & & \\
\hline & & & $\begin{array}{c}\text { Unión, } \\
\text { Progreso y } \\
\text { Libertad } \\
\text { de } \\
\text { Barranqui } \\
\text { tas }\end{array}$ & & & & \\
\hline & & & $\begin{array}{c}\text { Barranqui } \\
\text { tas Sur }\end{array}$ & & & & \\
\hline & & & $\begin{array}{l}\text { Reserva } \\
\text { Natural } \\
\text { del Oeste }\end{array}$ & $\begin{array}{l}\text { FFEM } \\
(31 \%)\end{array}$ & $\begin{array}{c}\text { Municipio } \\
(69 \%)\end{array}$ & $\begin{array}{c}\text { Restauració } \\
\text { n ecológica } \\
\text { del sitio / }\end{array}$ & $S / d$ \\
\hline
\end{tabular}




\begin{tabular}{|c|c|c|c|c|c|}
\hline & & & & $\begin{array}{c}\text { reubicación } \\
\text { de las } \\
\text { familias }\end{array}$ & \\
\hline \multirow{5}{*}{$\begin{array}{c}\text { PUI } \\
\text { Norest } \\
\text { e }\end{array}$} & \multirow{5}{*}{2012} & $\begin{array}{l}\text { Coronel } \\
\text { Dorrego }\end{array}$ & \multirow{5}{*}{$\begin{array}{l}\text { Nación, } \\
\text { Provincia y } \\
\text { Municipio }\end{array}$} & \multirow{5}{*}{$\begin{array}{c}\text { Iluminación } \\
\text { y apertura } \\
\text { de calles, } \\
\text { pavimento } \\
\text { articulado, } \\
\text { edificios } \\
\text { públicos, } \\
\text { construcción } \\
\text { de viviendas, } \\
\text { generación } \\
\text { de suelo } \\
\text { urbano }\end{array}$} & \\
\hline & & $\begin{array}{c}\text { Nueva } \\
\text { Esperanza } \\
\text { (Los } \\
\text { Quinchito } \\
\text { s) }\end{array}$ & & & $S / d$ \\
\hline & & $\begin{array}{l}\text { Guadalup } \\
\text { e Oeste }\end{array}$ & & & \\
\hline & & $\begin{array}{l}\text { Guadalup } \\
\text { e Noreste }\end{array}$ & & & \\
\hline & & $\begin{array}{l}\text { Guadalup } \\
\text { e Centro }\end{array}$ & & & \\
\hline
\end{tabular}

Fuente: elaboración propia realizada según nuestro trabajo de campo en base a información disponible de "Programas Urbanos Integrales" realizado por la Municipalidad de la Ciudad de Santa Fe -Agencia Santa Fe Hábitat, 2007.

¿Qué es lo que diferencia, a grandes rasgos, a estos dos programas integrales? Si bien ambos se encuentran destinados al mejoramiento integral de los barrios, y comparten entre sus componentes la regularización dominial del suelo, mientras que PROMEBA apunta al financiamiento de obras de infraestructura, tanto para el mejoramiento los sectores urbanos en general, así como dentro de las viviendas existentes que se localizan en esos sectores; los PUI lo hacen hacia la refuncionalización de estas áreas urbanas, pero a la par de la dotación de obras de infraestructuras, el énfasis está puesto en obras de equipamientos públicos y recreativos en estos sectores. Sin embargo, a diferencia de PROMEBA, cuya operacionalización fue articulada con el PRD de las viviendas existentes, los PUI incorporan como instrumento de gestión la relocalización de familias a nuevas viviendas, a partir del trabajo articulado con instituciones de la sociedad civil, para posteriormente, coordinar con el municipio en la regularización dominial.

Desde este repaso histórico, observamos cómo en los distritos más empobrecidos y con mayor cantidad de barrios en donde residen hogares en condiciones precarias de tenencia, se articularon históricamente el Plan Lote, el Programa de Erradicación de Ranchos del MSLT, así como el Programa de Regularización Dominial y los recientes Programas Urbanos Integrales (Cuadro $N^{\circ}$ 8). Es decir, los programas que mayor injerencia tienen hasta la fecha en relación a la regularización dominial en la ciudad (Mapa Nº). 
Cuadro 8 La construcción histórica del beneficiario: tenencia del suelo y programas urbanos según distritos, Santa Fe, 1895-2017.

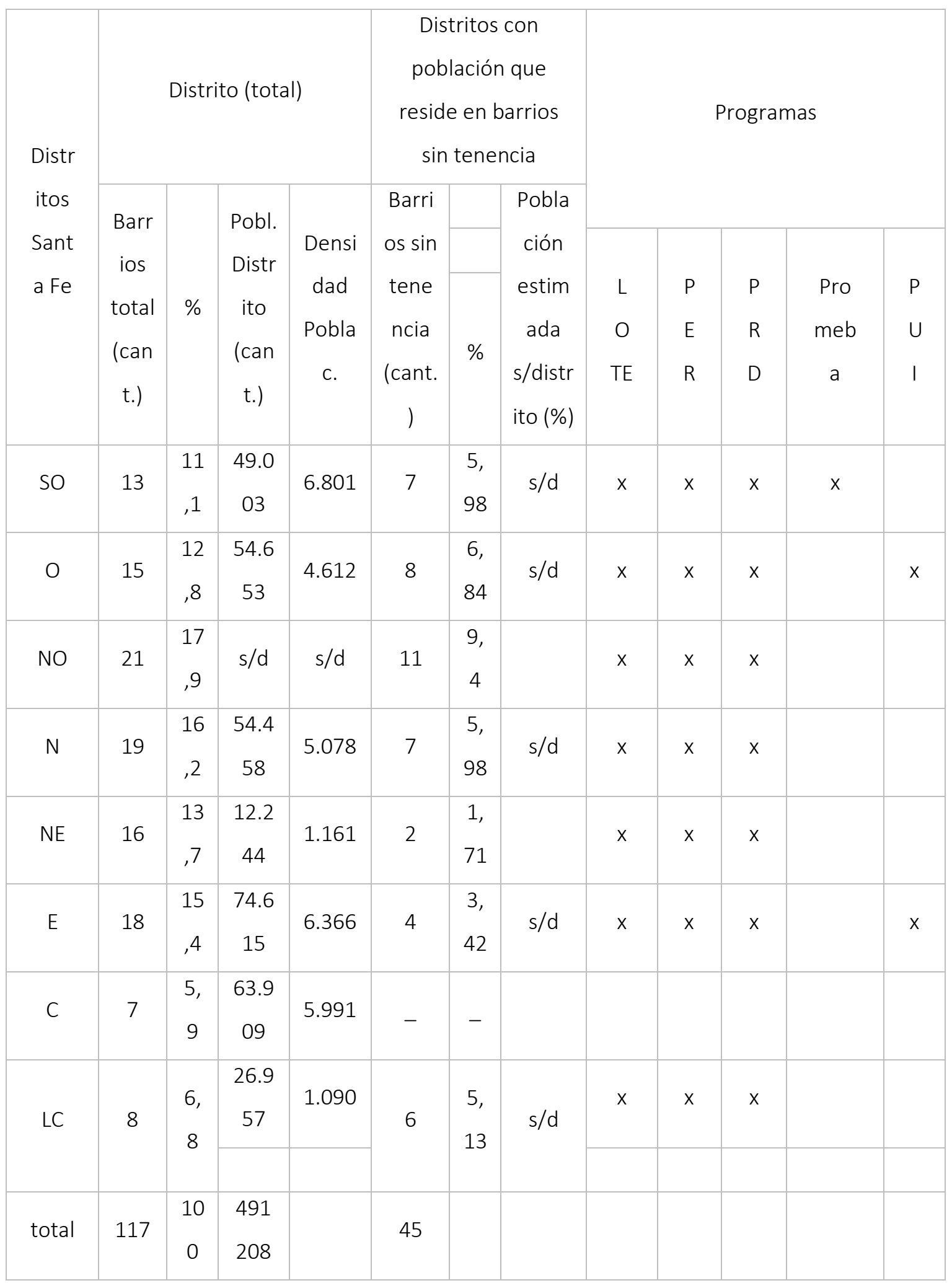

Fuente: Elaboración propia en base a datos obtenidos de los programas vistos. 
Mapa 8 La construcción histórica del beneficiario: localización de hogares con condiciones precarias de tenencia y programas vinculados a la regularización dominial, Santa Fe, 1985-2017

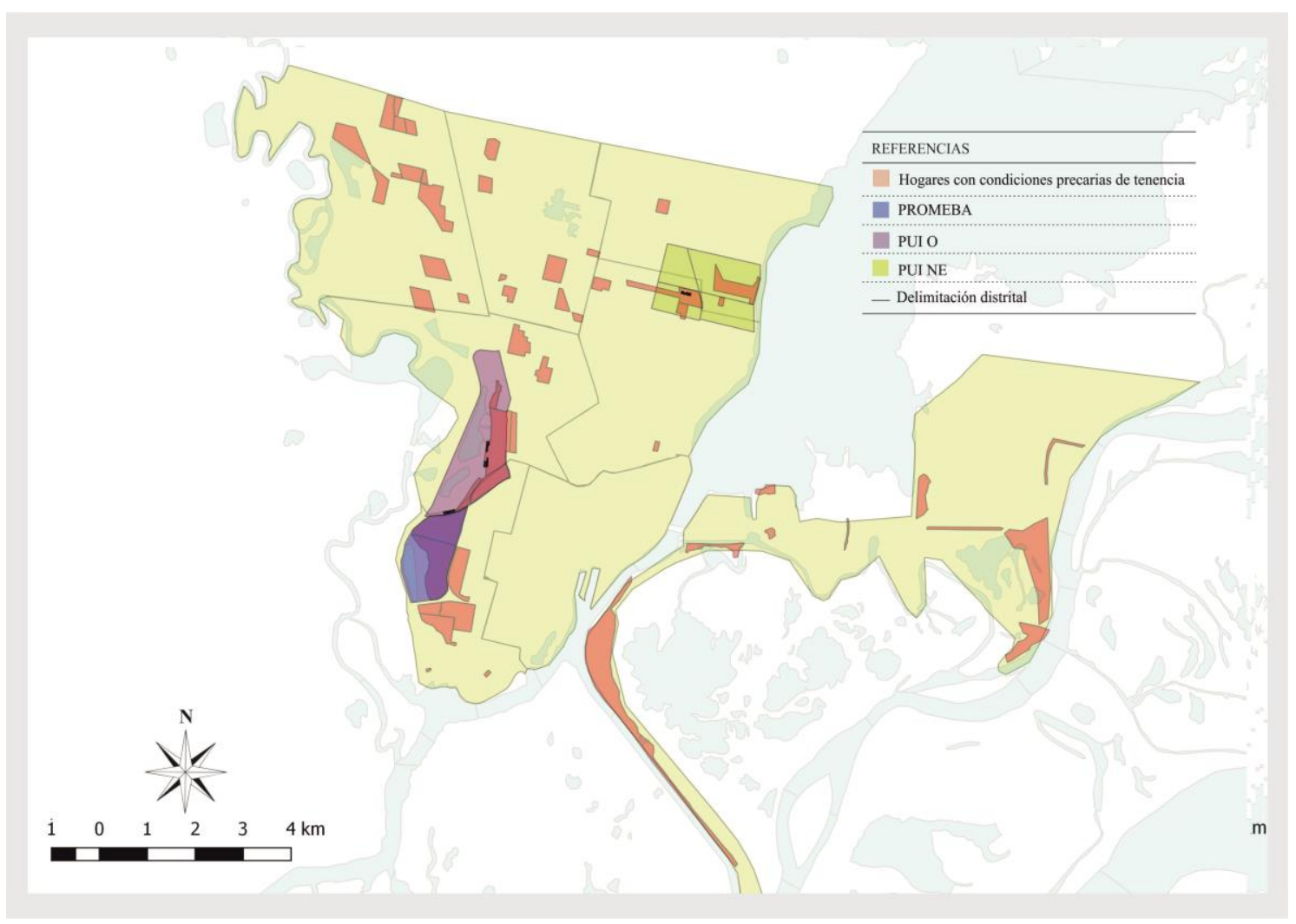

Nota: este mapa se corresponde con el Cuadro $N^{\circ} 8$. Fuente: Elaboración propia en base a datos obtenidos de los programas vistos.

\section{REFLEXIONES: LA CONSTRUCCIÓN HISTÓRICA DEL BENEFICIARIO}

A lo largo de este artículo realizamos un sucinto repaso histórico por los programas urbanos instrumentalizados en Santa $\mathrm{Fe}$ en las últimas tres décadas vinculados a la regularización dominial, centrándonos en la incidencia de los mismos en la conformación socioespacial de la ciudad, y específicamente, en la localización de la población empobrecida. En este marco, encontramos desde el inicio de la pesquita una correlación entre la conformación territorial de la ciudad, organizada de acuerdo a las relaciones sociales establecidas desde la colonia, es decir, desde la distribución social de tierras instituidas en la Ley de Indias, y su conformación actual. Este contexto fundacional fue reproducido, con el pasar de los años, 
abarcando una mayor cantidad de población e incrementando la superficie de suelo destinada al uso residencial. ¿Qué implicó esta división social del espacio? Dicho orden involucró la apropiación social de suelo localizado en óptimas condiciones ambientales, de infraestructuras y de servicios, entre otras cuestiones; principalmente de aquellas lonjas próximas al casco fundacional y posteriormente, hacia la franja ribereña al este y la franja este-oeste de los bulevares.

No obstante, esta conformación creó las condiciones para que aquellos suelos vacantes en condiciones precarias de habitabilidad, infraestructuras, localización, tenencia, etc., fueran apropiados paulatinamente por familias empobrecidas, expulsadas de aquellas áreas urbanas. Concurrió así como durante las primeras décadas del siglo XX, la franja oeste de la ciudad fue conformada, históricamente, como un borde precarizado. Este orden socio-espacial se vio reforzado paulatinamente desde mediados de la década de 1970, e incluyó también la apropiación de suelo vacante en condiciones precarias hacia el norte y el borde costero, fundamentalmente en aquellos sectores próximos a cauces pluviales. De esta manera, inferimos como la conformación de la ciudad no fue ajena al contexto socio-político internacional evidenciado en los países latinoamericanos en general, y en Argentina en particular, atravesado por una desigual distribución de la riqueza en continua perpetuación de la pobreza (Kowarick, L., 1977; Pradilla, 1983; Duhau, 2002; Núñez, 2011).

No obstante, desde mediados de la década de 1980 advertimos la instrumentalización en la ciudad de programas urbanos que buscaron paliar esta situación y tuvieron como objeto a hogares empobrecidos que residían en condiciones habitacionales y de tenencia precaria. En este contexto, Plan LOTE fue uno de los primeros antecedentes en la ciudad que buscó regularizar la situación dominial de hogares empobrecidos, tratándose en algunos casos de hogares que residían desde hacía, al menos, dos décadas; en simultáneo, el PER del MLST buscó mejorar estas condiciones a partir del otorgamiento de módulos habitacionales, mediante prácticas vinculadas a la autoconstrucción de viviendas. En este sentido, y según nuestro trabajo de campo (Autora, 2017b), si bien plan LOTE no logró un alcance amplio en su instrumentalización, el PER a partir de la interpelación ideológica de la vivienda, creó las condiciones socio-habitacionales para que, en varios casos, los hogares se localicen en zonas precarias, de riesgo hídrico y ambiental. Es decir, que este programa no sólo localizó a la población, sino que en simultáneo creó suelo urbano en condiciones precarias. Asimismo, si bien Plan LOTE entregó escrituras de dominio, predominó la entrega de boletos de compra- 
venta. El PER, por su parte, no otorgó ningún documento que acredite la propiedad, pero sí promulgó posteriormente la expropiación de estos terrenos ${ }^{31}$.

Dos décadas después, esta división social del espacio (Duhau, 2002) fue reforzada por otro programa que, en continuidad con los dos anteriores buscó mejorar las condiciones de vida de la población empobrecida también a partir de la regularización dominial de la propiedad privada: el PRD operacionalizado desde el 2009. Este programa, mientras promulgó la regularización dominial de los lotes, otorgó a su vez instrumentos de tenencia precaria. Posteriormente, en el año 2012 asistimos a la instrumentalización de los PUI, que a la par del mejoramiento de entorno barrial precarizado en donde residían hogares empobrecidos, comprendió también operatorias de regularización dominial, articulado con el PRD.

En este sentido y como coronario, reflexionamos dos cuestiones. La primera de ellas y a rasgos generales, es cómo pasadas las décadas y la operacionalización de distintos programas, inferimos una argamasa política instrumentalizada históricamente sobre los mismos sectores urbanos en donde residen familias designadas por diversas instituciones como beneficiarias: de múltiples planes sociales, programas, viviendas mínimas, y demás instrumentos de política urbana. No obstante a esta instrumentalización, en algunos casos coexisten diversas generaciones del grupo familiar residiendo sobre estos terrenos y autoconstruyendo sus viviendas; y en otros casos, al no disponer de la propiedad los hogares se ven forzadas a desplazarse, producto también de la propia política (Autora, 2017b).

La segunda reflexión, y en lo particular, es cómo mientras los programas analizados incorporan diversos instrumentos de política que avalan presuntamente la propiedad privada, la contradicen: así como en su momento plan LOTE entregó boletos de compraventa a los hogares, y fue este el único documento como acreditación de la propiedad, el PRD en la mayoría de los casos otorgó a los hogares instrumentos de tenencia intermedios (Chiclevsky, 2006:60) que no garantizan la propiedad; como ser las actas de tenencia o adjudicación, las constancias de ocupación, y los boletos de cancelación de deuda. En los casos en donde los hogares recibieron las escrituras, esto implicó asimismo que hayan atravesado diversas instancias burocráticas previas antes de obtener esta documentación (Autora, 2017b).

\footnotetext{
${ }^{31}$ No obstante, varios de los asentamientos relevados por Plan Lote, tanto en 1985 como en 1995, fueron captados por el PRD, aunque también se incluyeron en este programa sectores urbanos precarizados correspondientes al PER. Es decir, el PRD, no sólo incorporó nuevos hogares residiendo en condiciones precarias de tenencia, sino que a su vez retomó como población objeto a familias que, al menos, desde la década de 1980 ya residían en estas condiciones.
} 
No obstante, y tal como vimos en el transcurso de este artículo, actualmente la mayoría de los hogares que residen históricamente en sectores urbanos sin documentos que acrediten la propiedad del suelo, es decir, con condiciones precarias de tenencia, sólo disponen de los documentos precarios de tenencia mencionados recientemente que, como bien sabemos, jurídicamente no garantizan la propiedad, “...pues obviamente que dichas tenencias entrañan peligro de desalojo, dado que poseen vulnerabilidad jurídica..." (Chiclevsky, 2006:60). Es decir, se trata de la propia política pública que reproduce condiciones de tenencia precaria. Con esto inferimos la instrumentalización histórica de una política que promulga, avala y defiende la regularización dominial del suelo, pero que cuantitativamente no condice con los resultados obtenidos.

\section{REFERENCIAS BIBLIOGRÁFICAS}

ANÓNIMO. Entrevista ex trabajador Plan Lote. Entrevista personal, entrevistada por Autora, [Grabador / mp3], Santa Fe, 18/04/2017.

AGENCIA SANTA FE HÁBITAT. Diagnóstico urbano realizado por la Municipalidad de la Ciudad de Santa Fe. Documento de trabajo. Santa Fe: Agencia Santa Fe Hábitat, 2007

AGENCIA SANTA FE HÁBITAT. Premio a la Innovación Centro de Implementación de Políticas Públicas para la Equidad y el Crecimiento -CIPPEC. Formulario para Premio a la Innovación del Centro de Implementación de Políticas Públicas para la Equidad y el Crecimiento -CIPPEC, Santa Fe: Agencia Santa Fe Hábitat, 2011.

CALVO, Luis María. Santa Fe la Vieja (1573-1660). La ocupación del territorio y la determinación del espacio en una ciudad hispanoamericana. Santa Fe: ServGraf, 1990

CALVO, Luis María. Vivienda y ciudad colonial. El caso de Santa Fe. Santa Fe: Universidad Nacional del Litoral, 2011.

CLICHLEVSKY, Nora. Regularizando la informalidad del suelo en América Latina y el Caribe. Una evaluación sobre la base de 13 países y 71 programas. Proyecto CEPAL 'Pobreza urbana: 
estrategia orientada a la acción para los gobiernos e instituciones municipales de América Latina y el Caribe', Santiago de Chile: Comisión Económica para América Latina y el Caribe Organización Naciones Unidas, 2006.

DUHAU, Emilio. Dimensiones socio-políticas de la irregularidad y La regularización de los asentamientos populares, Lincoln Institute of Land Policy [en línea], Lincoln Institute of Land Policy;

Cambridge, <http://www.institutodeestudiosurbanos.info/dmdocuments/cendocieu/Especializacion_Merca dos/Documentos_Cursos/Dimensiones_Socio_Politicas-Duhau_Emilio-2002.pdf> 17 de noviembre de 2002

DUHAU, Emilio. La división social del espacio metropolitano. Una propuesta de análisis. En Nueva Sociedad, Buenos Aires, n. 243, p. 79-9, enero/febrero, 2013.

FERNANDES, Edesio. Programas de regularización de la tenencia de la tierra urbana y pobreza urbana en Latinoamérica, Revista Vivienda Popular, Montevideo, n. 12, p. 5-16, 2003.

GIORIA, Blanca. La construcción del espacio geográfico de la ciudad de Santa Fe 1573-2007. Santa Fe: Ministerio de Innovación y Cultura, 2009.

GÓMEZ, Néstor, Segregación residencial en el Gran Santa Fe a comienzos del siglo XXI. Bitácora Urbano Territorial, Bogotá, v. 2, n 19, p. 63-74, 2011.

GÓMEZ, Néstor y PERETTI, Gustavo. Territorio, población y expansión de la ciudad de Santa Fe durante el siglo XX. En Platino, María Florencia (coord.), Convivir Con El Río, Santa Fe. Municipalidad de la Ciudad de Santa Fe, Fascículo 13 - 1a ed. -. 2013.

KOWARICK, Lucio. Capitalismo e marginalidade na América Latina. 2. Ed. Río de Janeiro: Paz e Terra, 1977.

KOWARICK, Lucio. Estudos urbanos. Sao Paulo: Editora 34, 2000. 
KOZAK, Daniel. John F.C. Turner y el debate sobre la participación populare n la producción de hábitat en américa latina en la cultura arquitectónico-urbanística, 1961-1976. Revista Electrónica Centro Interdisciplinar Estudos, Campinas, n. 8 (3), p.49-68, 2016.

Autora. x. Cuaderno Urbano, Resistencia: Nobuko, n. 22, pp. 91-110, 2017ạ.

Autora. x. Tesis de doctorado, Universidad Nacional de Rosario, Argentina. 2017b.

MOVIMIENTO LOS SIN TECHO. El sector marginado en Santa Fe. Un informe para debatir y preparar el futuro de Santa Fe. Informe. Santa Fe: Movimiento Los Sin Techo, 1996.

MOVIMIENTO LOS SIN TECHO. Voces de los Sin Techo. Haciendo pedagogía desde la marginalidad. 2da. Edición. Santa Fe: Impresossa, 2014.

MURILLO, Susana (comp.). Neoliberalismo y gobiernos de la vida. Diagrama global y despliegues en Argentina y América Latina. 1era. ed.- Buenos Aires: Biblos, 2015.

NÚÑEZ, Ana y CIUFFOLINI, Alejandra, (Comp.). Políticas y territorialidad en tres ciudades Argentinas. Buenos Aires: El Colectivo, 2011

NÚÑEZ, Ana. Miserias de la propiedad: apropiación del espacio, familia y clase social. Mar del Plata: EUDEM, 2012.

PRADILLA, Emilio. El problema de la vivienda en América Latina. Quito, Centro de Investigaciones Ciudad, 1983.

PRADILLA, Emilio. Contribución a la crítica de la 'teoría urbana' del 'espacio' a la 'crisis' urbana. Ciudad de México, Editorial U.A.M., 1984.

SARA LAURIA, Entrevista Directora de la Agencia Santa Fe Hábitat. Entrevista personal, entrevistada por Autora, [Grabador / mp3], Santa Fe, 12/05/2017. 
SMOLKA, Martín. Preco da terra e valorizacão Imobiliária: Esboco para o Enquadramento Conceitual da Questão. Texto para Discussao Interna, Instituto de Planejamento Economico e Social n. 12., p.1-38, Dic, 1979.

SOIJET, Mirta (comp.). Agenda Metropolitana Santa Fe-Paraná. Santa Fe: Universidad Nacional del Litoral, 2011.

Trabalho enviado em 25 de julho de 2018

Aceito em 01 de janeiro de 2019 